\title{
PII: S0301-0082(97)00094-4
}

\section{A STRUCTURAL BASIS FOR MEMORY STORAGE IN MAMMALS}

\author{
NANCY J. WOOLF* \\ Laboratory of Chemical Neuroanatomy and Department of Psychology, University of California, Los \\ Angeles, CA 90095-1563, USA
}

(Received 6 October 1997)

\begin{abstract}
It is proposed that altered dendrite length and de novo formation of new dendrite branches in cholinoceptive cells are responsible for long-term memory storage, a process enabled by the degradation of microtubule-associated protein-2. These memories are encoded as modality-specific associable representations. Accordingly, associable representations are confined to cytoarchitectonic modules of the cerebral cortex, hippocampus, and amygdala. The proposed sequence of events leading to long-term storage in cholinoceptive dendrites begins with changes in neuronal activity, then in neurotrophin release, followed by enhanced acetylcholine release, muscarinic response, calcium influx, degradation of microtubule-associated protein-2, and finally new dendrite structure. Hypothetically, each associable representation consists of altered dendrite segments from approximately 5000-15000 cholinoceptive cells contained within one or a few module(s). Simultaneous restructuring during consolidation of long-term memory is hypothesized to result in a similar infrastructure among dendrite sets, facilitating co-activation of those dendrite sets by neurotransmitters such as acetylcholine, and conceivably enabling high energy interactions between those dendrites by phenomena such as quantum optical coherence. Based on the specific architecture proposed, it is estimated that the human telencephalon contains enough dendrites to encode 50 million associable representations in a lifetime, or put another way, to encode one new associable representation each minute. The implications that this proposal has regarding treatments for Alzheimer's disease are also discussed. (C) 1998 Elsevier Science Ltd. All rights reserved
\end{abstract}

\section{CONTENTS}

1. Introduction

2. Types of memory and related issues

2.1. Sensory memory and sensory processing

2.2. Short-term memory

2.3. Long-term memory

3. Cholinergic innervation of the telencephalic mantle

3.1. Modules in the cerebral cortex

3.2. Hippocampal sectors resemble modules

3.3. Amygdalar nuclei resemble modules

4. Hypothetical sequence of events surrounding memory encoding

4.1. Enhanced electrical activity

4.2. Induction of neurotrophins

4.3. Changes in cholinergic terminals

4.4. Elevated muscarinic receptor activity

4.5. Protein kinase activation and MAP-2 phosphorylation

4.6. Increased intracellular $\mathrm{Ca}^{2+}$ and protease-mediated breakdown of MAP-2

4.7. Altered dendritic structure and companion axonal change

5. Predictions based on the hypothesis

5.1. The structure of information storage

5.2. Memory capacity: infinite or finite?

5.3. Memory storage and aging

6. Conclusions

References

\section{ABBREVIATIONS}

BDNF brain-derived neurotrophic factor

ChAT choline acetyltransferase

CS conditioned stimulus

LTP long term potentiation

MAP-2 microtubule-associated protein-2

$\begin{array}{ll}\text { NGF } & \text { nerve growth factor } \\ \text { NMDA } & \text { N-methyl-D-aspartate } \\ \text { NT-3 } & \text { neurotrophin-3 } \\ \text { PKC } & \text { protein kinase C } \\ \text { US } & \text { unconditioned stimulus }\end{array}$

*E-mail: nwoolf@ucla.edu,woolf@psych.ucla.edu. 


\section{INTRODUCTION}

There has been a long quest for understanding the neurobiology of human memory. Starting with Karl Lashley (1950) and Donald Hebb (1949), if not earlier (see Tanzi, 1893; Cajal, 1928), we encounter notions regarding how an enduring memory trace or "engram" might be formed with learning. The engram is by definition a functional and physical change in the brain. By implication, the molecules involved with the engram are those intimately related to neuronal function and structure. Currently, there is a great deal known about many of the various molecules found in the brain. In this paper, I will propose a hypothetical sequence of molecular events in the nervous system that could account for memory storage in cholinoceptive cells, then discuss the strengths and weaknesses of that proposal, and finally suggest experiments to test the model.

The hypothetical sequence presented here elaborates on how fluctuations in the release of acetylcholine could alter cortical circuitry and thereby permanently encode memory. This seems appropriate since cortical release of acetylcholine has an established role in memory, or perhaps more precisely in selective attentional processes that enable memory (for recent reviews see Wenk, 1997; Sarter and Bruno, 1997; for earlier reviews see Drachman, 1977; Bartus et al., 1982). Moreover, the cholinergic deficit remains a prominent hallmark of Alzheimer's disease (for recent reviews see Brion, 1996; Mesulam, 1996; Palmer, 1996): a finding that has been validated many times since its initial description (Bowen et al., 1976). Of particular importance to the idea that cholinergic systems play a role in memory is the fact that the degree of intellectual impairment shown in patients with Alzheimer's disease is correlated with the degree to which cholinergic enzymes are depleted (Perry et al., 1978; Palmer, 1996). Also, cell losses in the cholinergic basal forebrain-which includes the telencephalic projection neurons in the nucleus basalis and medial septal nucleus - continue to be found in postmortem tissue from patients diagnosed with Alzheimer's disease (Whitehouse et al., 1981; Boissiere et al., 1997).

The results of many animal studies support a cholinergic role in memory; however, some animal studies provide data that challenges this view. Spatial memory, in particular, appears to rely heavily on the rostral part of the basal forebrain-namely the septohippcampal system (see Muir, 1997). Selective lesions of cholinergic basal forebrain neurons made with the immunotoxin, IgG 192-saporin, have produced dose-dependent deficits in short-term spatial or discriminative memory (Waite et al., 1995; Lezana et al., 1996; Walsh et al., 1996; Shen et al., 1996). However, spatial learning deficits were not apparent in a number of other studies using $\mathrm{IgG}$ 192-saporin (see Baxter et al., 1996; McMahan et al., 1997). Accordingly, some authors feel that the role acetylcholine plays in memory has been overstated (see Blokland, 1995).

Another criticism of the cholinergic hypothesis of memory is that it ignores the contributions of other neurotransmitters. By focusing on acetylcholine in this paper, I do not mean to imply that acetylcholine is the only cortical neurotransmitter system involved in memory. The interaction between acetylcholine and glutamate, especially the interaction between muscarinic acetylcholine receptors with NMDA glutamate receptors, is notably critical to memory and will be discussed more fully in Sections 4.1, 4.5 and 4.6. Also, the monoamine transmitters appear to perform many of the same functions as do cholinergic neurons, and monoaminergic neurons may substitute for the cholinergic system under certain circumstances. This is shown by pharmacological studies in which blockade of the cholinergic system only impairs memory, whereas combined blockade of the cholinergic and either the serotonergic or noradrenergic system can totally disrupt memory function (Vanderwolf, 1987; Ohno et al., 1997). Similarly, cholinergic systems appear to interact with dopamine systems in memory tasks (Hersi et al., 1995). The results of all these experiments suggest that cholinergic and monoaminergic systems may operate cooperatively during memory formation.

The theme of this paper is not to argue "if" the cholinergic systems participate in memory, but rather to argue "how" they might participate. Certainly, the former question has been covered in many thorough reviews (e.g., Muir, 1997; Sarter and Bruno, 1997; Wenk, 1997). Also, other investigators have addressed the issue of how cholinergic systems participate in higher cognitive functions from different perspectives, for example, through neural network modeling (Hasselmo et al., 1996; Myers et al., 1996). In this paper, I will review recent research pertaining to the plasticity of cholinoceptive cells, in particular, the evidence that cholinoceptive cell dendrites undergo restructuring during memory formation. Changes in the cholinoceptive cell dendrites may not be entirely under the modulatory guidance of acetylcholine, however. Cortical synapses releasing other neurotransmitters may also modulate these dendrites. Nonetheless, the present focus will be on cholinoceptive cell dendrites and their cholinergic afferents. From the perspective of neuroplasticity with behavioral conditioning, there are several pieces of evidence suggesting that the cholinoceptive cells are prominently involved in memory encoding.

Acetylcholine release in the cerebral cortex appears to be largely responsible for cortical response adaptation attendant with behavioral conditioning. Mednikova (1990) found that most conditionally responsive cells were cholinoceptive; only one cell that was not conditionally reactive responded to acetylcholine. The correlation between participation in conditioning and sensitivity to acetylcholine was statistically significant. In another series of experiments, conditional changes in cortical cells depended on acetylcholine in approximately 90\% of cells recorded (Rigdon and Pirch, 1986; Pirch et al., 1992). This is quite a remarkable correspondence considering that only $14-16 \%$ of cortical cells appear to be cholinoceptive. Krnjević and Phillis (1963) recorded from 1367 cortical cells, including the ordinarily "silent" cells, and found that only $14.6 \%$ of cortical neurons respond to acetylcholine. Counts of cell bodies reacting to antibodies against muscarinic receptor or acetylcholin- 
esterase histochemistry similarly showed that $15.6 \%$ or $14.7 \%$ of cells in cerebral cortex are cholinoceptive (Woolf, 1993).

Every cholinoceptive cell is furthermore enriched with abundant amounts of the labile cytoskeletal protein: microtubule-associated protein-2 (MAP-2), and conversely, $80 \%$ of MAP- 2 rich cells are cholinoceptive (Woolf, 1993). The localization of MAP-2 also appears to be related to behavioral conditioning. Pavlovian conditioning and contextual learning alters immunohistochemical reactions for MAP-2 (Woolf et al., 1994, 1996). Here we are talking about three relatively small, select cell populations that overlap almost perfectly - namely cells showing conditional electrophysiological adaptation, conditional cytoskeletal protein change, and receptivity to acetylcholine. It seems highly unlikely that these correspondences are not functionally relevant.

Also, cholinergic afferent axons have terminal fields restricted to modality-specific modules of cortex thereby enabling them to modulate cortical processing of modality-specific stimuli, conceivably in relation to memory formation (see Section 3.1). The functional importance of the cortical module is illustrated in our studies showing memory-related MAP2 alterations occur in entire sets of cholinoceptive neurons organized within discrete modules of cerebral cortex or discrete sectors of hippocampus (Woolf et al., 1994, 1996). Thus, the cholinoceptive cells and their modifiable dendrites that are organized within discrete modules arguably serve as "engram units" in the cortex and hippocampus.

Cholinoceptive dendrites do receive cholinergic inputs, but we must keep in mind that they also receive input from virtually every neurotransmitter system in the cerebral cortex. The $20 \%$ of MAP-2 rich cells that are not cholinoceptive may constitute another group of memory-related cells that respond exclusively to other neurotransmitters. Nonetheless, the cholinoceptive cells would appear to be the largest set of engram units. A preliminary way to test this idea is to evaluate what is presently known about cholinergic involvement in the specific stages of memory. In the next section, we will consider the stages of memory storage and memory-related phenomena, such as attention.

\section{TYPES OF MEMORY AND RELATED ISSUES}

Memory can last a fraction of a second or a lifetime. Memory experts often speak of different stages or types of memory: the three most basic types of memory evident in humans and possibly in laboratory animals are sensory, short-term, and long-term memory (see Squire, 1986; Baddeley, 1992). Unfortunately, the distinctions between sensory, short-term, and long-term memory are not always clear-cut. In particular, the time it takes for information in short-term memory to enter permanent long-term storage varies. Thus, any neurobiological model of memory must take this into account.

Memory storage in cholinoceptive cells is proposed to occur according to the following sequence of events. First, the amount and distribution of acetylcholine released into specific regions of the cerebral cortex and hippocampus controls ongoing sensory processing and the organism's attention level. The cholinergic basal forebrain neurons possess this capability because they receive relays originating from cholinergic and monoaminergic neurons in the brainstem that integrate information they receive from multimodal sensory fiber collaterals (see Woolf and Butcher, 1986; Woolf, 1996a). This sensory processing is transient, being updated approximately each half second (the time interval may actually vary from $150-700 \mathrm{msec}$ ). Since most sensory information is lost within a fraction of a second, the process of sensory encoding may be comparable to the very brief sensory memory. Stimuli allocated a greater degree of attention, however, may move on to short-term memory encoding. In this case, we would expect a prolonged elevation in acetylcholine release at specific cortical sites - the distribution of these sites would be organized according to the modality specific structure of the cerebral cortex. Shortterm memory would last as long as enhanced release of acetylcholine could be maintained.

At some point, acetylcholine release would be expected to return to baseline; nonetheless, the same spatial distribution of enhanced release could be reinstated at a later time (see Woolf, 1996a,b). Recurring bouts of enhanced release could conceivably continue over weeks, months, or years, just as consolidation into long-term memory storage takes variable amounts of time. A permanent storage form that would replace enhanced release of acetylcholine would greatly benefit the organism, for one, because the allocation of cholinergic control to one function takes away from its participation in another (see Callaway et al., 1992).

The long-term storage or engram envisioned here is dendritic change in distributed sets of cholinoceptive cells. These changes might include modification of dendrite length and the de novo formation of distal dendrite branches. Hypothetically, these dendritic changes would enable selective attention to stimuli in the presence of moderate, rather than elevated, levels of acetylcholine release. Later (see Section 5.1), I will elaborate on how modified sets of distal branches might provide long-term storage of complex information. Along with changes to the cholinoceptive cell dendrites, spatial reorganization of cholinergic terminals is predicted. These reorganized terminals could participate in retrieval of information, but since the cholinoceptive cells receive other inputs, other neurotransmitter systems could evoke retrieval, as well.

To test the feasibility of this model, I will compare and contrast studies of cholinergic antagonism in human and animal subjects. Many studies have described various types of cognitive impairment following the administration of cholinergic antagonists. The non-selective muscarinic antagonist, scopolamine, has been used extensively, in part, because it can be readily administered to human and animal subjects. Thus, a large number of studies using scopolamine are available for comparison. Nonetheless, the central effects of scopolamine are not straightforward. Scopolamine blocks presynaptic autoreceptors, as well as postsynaptic receptors: antagonism 
of presynaptic autoreceptors by scopolamine leads to increased acetylcholine release (Vannucchi and Pepeu, 1995). Another approach is to selectively lesion cholinergic basal forebrain cells. There are contradictory results, along with a general consensus among both pharmacological and lesion studies. These will be discussed for each specific type of memory.

\subsection{Sensory Memory and Sensory Processing}

Approximately 2 to 3 times per sec, particular sets of incoming information are held in very brief sensory storage. Visual sensory memory is also called iconic memory and the brief sensory memory of auditory events is called echoic memory. Temporal summation of inputs to cholinergic cells within their endogenously occurring firing cycles has been proposed as a basis of the brief sensory memory (Woolf, 1996a); however, there is only a small amount of direct evidence for this. Scopolamine administered to human subjects, for example, seems to impair rapid information processing (Wesnes and Warburton, 1984). Also, IgG 192 saporin lesions of the basal forebrain impair discrimination to very brief stimuli, especially in aged animals (Stoehr et al., 1997). Nonetheless, there are far too few experimental data available to make any firm conclusion. Thus, the involvement of cholinergic neurons in the very brief sensory memory remains speculative. There are abundant data, however, supporting a cholinergic role in sensory processing in general (see Wenk, 1997; Sarter and Bruno, 1997).

\subsection{Short-Term Memory}

A large number of studies support a role for acetylcholine in short-term memory and the acquisition of new information. The majority of studies using scopolamine show impaired encoding of new memory in humans, primates, and rodents (for review see Hasselmo et al., 1996). However, other studies using scopolamine suggest that the drug disrupts attentional processes rather than memory (Cheal, 1981).

As described in the introduction of this paper, recent studies using the selective cholinotoxin, IgG 192 saporin, also produce mixed results. A possible factor for these mixed results may be the task; radial arm maze performance may be more susceptible to impairment than performance on the Morris water maze (Dornan et al., 1996). Another critical factor is the degree of cholinergic depletion. Waite and colleagues (1995) found IgG 192 saporin produced severe dose-dependent short-term memory impairments only when there was a $>90 \%$ reduction of choline acetyltransferase. But even high doses of IgG 192 saporin do not completely destroy the cholinergic basal forebrain system. This is illustrated by another study in which short-term memory deficits resulting from a 90-95\% depletion of cholinergic neurons were further exacerbated by the administration of scopolamine (Lezana et al., 1996). The immunotoxin, IgG192 saporin, will never accomplish total destruction of the cholinergic basal forebrain because there is a population of basal forebrain cholinergic cells that project to the amygdala and adjacent limbic cortices that are not sensitive to the immunotoxin (Heckers et al., 1994). It is conceivable that new selective neurotoxins will target all the cholinergic basal forebrain cells. A recent approach employing immune-mediated damage to cholinergic medial septal cells causes mnemonic deficits and this method may cause more complete damage to cholinergic neurons (Kalman et al., 1997).

Yet another possible way of reconciling the apparently discrepant findings between different IgG 192 saporin studies is to conclude that the cholinergic basal forebrain neurons play a role in selective attention rather than short-term memory (for review see Sarter and Bruno, 1997; Wenk, 1997). We are then left to determine how selective or focused attention and short-term memory are related. Cowan (1995) proposes an integrated framework for attention and memory. The hypothetical model for short-term memory proposed in this paper similarly includes selective attention as a component of shortterm memory and is thereby consistent with both interpretations of the IgG 192 saporin results.

\subsection{Long-Term Memory}

Scopolamine appears to be less disruptive to longterm memory storage than to short-term memory (Bartolini et al., 1992; Moran, 1993; Givens and Olton, 1994). Once a memory has been consolidated, it may no longer be susceptible to disruption by scopolamine. When scopolamine was administered at different times during the post-acquisition period of a spatial discrimination task, it took at least $3 \mathrm{hr}$ for long-term retention of the task to become resilient to the effects of scopolamine (Toumane and Durkin, 1993).

The relative resilience of long-term memory to cholinergic antagonists is consistent with the present model. As will be discussed in Section 4, the biochemical cascade leading to dendritic reorganization may be initiated immediately, as we have observed in the cerebral cortex (Woolf et al., 1994), or it may be delayed for weeks, as we have observed in the hippocampus (Woolf et al., 1996). Once the process for altering dendrites is initiated, cholinergic input may no longer be necessary. Nonetheless, cholinergic blockade might be expected to impair retrieval.

Studies evaluating acetylcholine and memory retrieval have yielded mixed results. In one study using human subjects, scopolamine disrupted retrieval of items in a free recall test (Rusted and Warburton, 1989), whereas, another study using human subjects failed to find a cholinergic role in retrieval processes (Vitiello et al., 1997). Some animal studies also indicate scopolamine interferes with retrieval (Beatty and Bierley, 1986; Molinengo, 1993), as do basal forebrain lesions (Murai et al., 1995). Riekkinen and Riekkinen (1997), however, provide data implicating NMDA receptors rather than muscarinic receptors in retrieval.

To summarize, cholinergic mechanisms are implicated in selective attention and short-term memory to a much greater extent than in long-term memory. Retrieval from long-term memory storage, however, 
may be mediated by acetylcholine, at least in part. To further understand these roles, we will consider the topography of cholinergic innervation of the mammalian telencephalon next.

\section{CHOLINERGIC INNERVATION OF THE TELENCEPHALIC MANTLE}

The cholinoceptive cells of the cerebral mantle are diverse in cell type (see Fig. 1) but all share one important feature: they receive inputs from an interconnected collection of cholinergic neurons located at the base of the telencephalon - the cholinergic basal forebrain. Cholinergic neurons in the basal forebrain innervate the entire telencephalic mantle, including the cerebral cortex, hippocampal formation, and amygdala (for reviews see Wainer and Mesulam, 1990; Woolf, 1991).

An overview of the topography of cholinergic innervation suggests that limbic cortex is innervated by the more rostral and medial cholinergic cells and the neocortex is innervated by more caudal and lateral cholinergic cells. Each cholinergic cell innervates one cortical area, and neighboring cholinergic cells often innervate different, even distant, cortical areas. Thus, there is great potential for coordinated activation of telencephalic regions that are nearby, as well as, far apart (see Woolf, 1996a,b).

The components of the cholinergic basal forebrain can be referred to in two ways. One method is to use

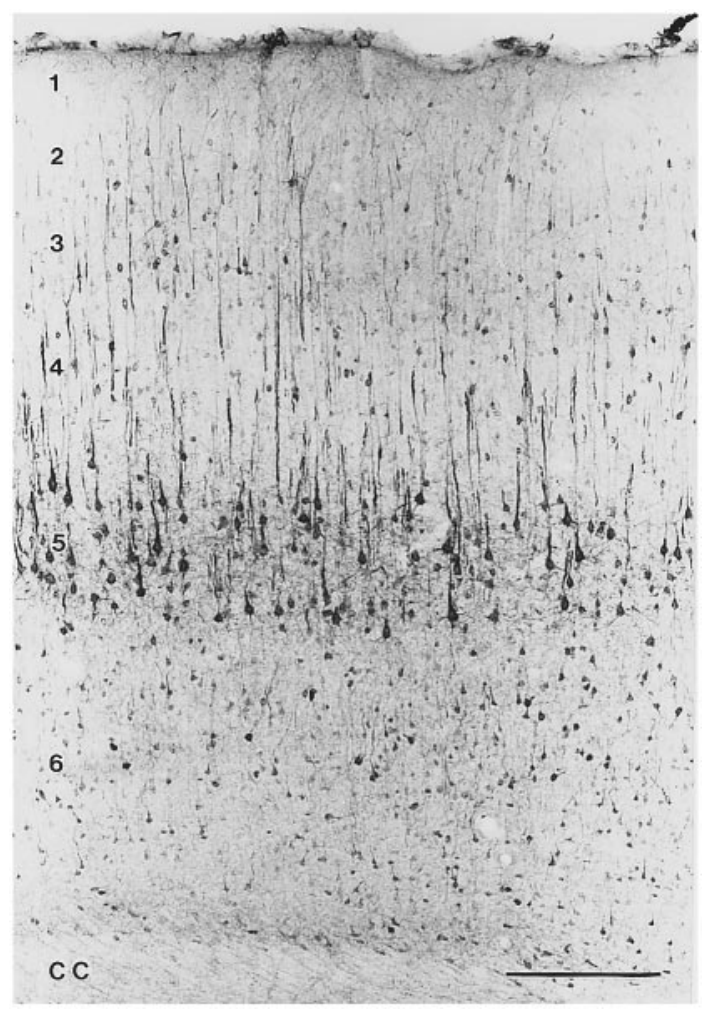

Fig. 1. Immunohistochemic staining for muscarinic receptor using the M35 antibody. Reprinted with permission from Elsevier Science, Amsterdam (Woolf, 1993). Cortical layers are labeled 1-6; CC: corpus callosum. Scale bar: $150 \mu \mathrm{m}$. the anatomical terms that were associated with those regions before the cholinergic neurons were discovered; another method is to use the nomenclature Ch1-Ch4 based on the location of cholinergic cell bodies. The medial septal nucleus (Ch1) and nucleus of the vertical limb of the diagonal band (Ch2) preferentially innervate the hippocampus and nearby limbic cortex (Woolf et al., 1984; Wainer and Mesulam, 1990). In the rat, the simple majority of these septohippocampal neurons, about $60 \%$, are cholinergic (Woolf et al., 1984). The nucleus of the horizontal limb of the diagonal band (Ch3), magnocellular preoptic area, substantia innominata, and nucleus basalis (Ch4), in this order, constitute a rostral-to-caudal collective of cholinergic neurons that innervates parts of the limbic cortex, the amygdala, and neocortex (Wainer and Mesulam, 1990; Woolf, 1991). In the rat, nearly all the cells with neocortical projections are cholinergic (Woolf et al., 1983). The same general scheme holds for cholinergic projections in the primate (for review see Wainer and Mesulam, 1990).

\subsection{Modules in the Cerebral Cortex}

The neocortex is divided into cytoarchitectonic regions related to specialized cortical functions. Each cytoarchitecturally-defined region assumes a particular function that is constrained by the sensory modality of its thalamic input. As is well known, this thalamic input is a point-to-point representation of a sensory modality: visual cortices are retinotopic, auditory cortices are tonotopic, somatosensory cortices are somatotopic, and so forth. Mountcastle (1987) recognized the fundamental importance of this organization and proposed that distributed activity in selected sets of modules is the neural correlate of higher cognitive function.

The cholinergic innervation of the neocortex obeys this principle of modular organization. Individual cytoarchitectonic regions of cortex, which might also be called modules, are innervated by discrete groups of cholinergic cells: these cytoarchitectonic regions measure, at most, $1-2 \mathrm{~mm}^{2}$ in rat brain (Bigl et al., 1982; Price and Stern, 1983; Saper, 1984). The cholinoceptive cells in each module are of all types; large pyramidal, small pyramidal, and non-pyramidal (Fig. 1). Nearly all the cholinoceptive cells are intensely immunoreactive for MAP-2, as well (Woolf, 1993). By virtue of their size, the large pyramidal cells contain the most MAP-2, within which this cytoskeletal protein is localized to the soma, the apical dendrite, and some side-branches (see Fig. 2).

The importance of the module is indicated in our experiments with MAP-2. In rats trained to associate a tone with a fear-producing shock, MAP-2 immunohistochemistry was enhanced in cholinoceptive cells confined to discrete cytoarchitectonic regions of the auditory cortex (Woolf et al., 1994). In this experiment, MAP-2 changes occurred largely in $\mathrm{Te} 2$ and $\mathrm{Te} 3$, cytoarchitectonic regions corresponding with association auditory cortex in the rat. Curiously, the MAP-2 cells in which the immunohistochemical reaction was enhanced had larger somal areas compared to control animals (Woolf et al., 1994). The uniformity of this change made affected 


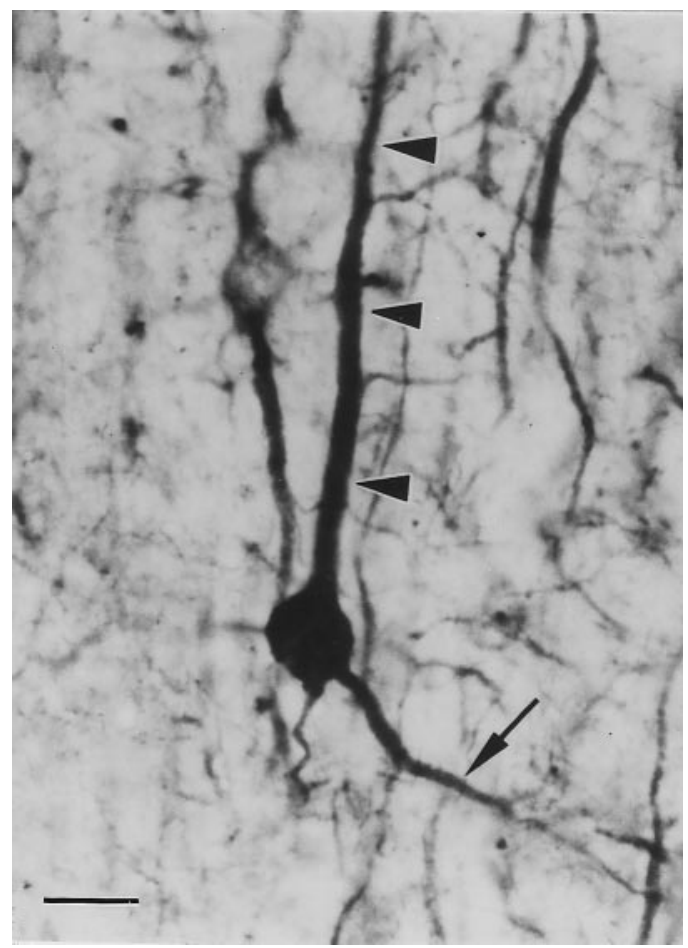

Fig. 2. A cortical pyramidal cell immunostained for MAP2. Arrowheads point to the heavily stained apical dendrite. Note immunostained side-branches emanating from the apical dendrite. The arrow points to a basilar dendrite. Scale bar: $20 \mu \mathrm{m}$.

areas stand out upon microscopic inspection, much as do cytoarchitectonic regions. Thus, it is not unreasonable to entertain the possibility that cytoarchitectonic features that distinguish one area from the next are dynamic, not static. Recent reorganization due to memory function-at least in part-may determine how readily one area of cortex can be distinguished from adjacent areas. This could explain why all brains do not show equally well a delineation between various cytoarchitectonic fields - a reason why the early attempts to parcel the human neocortex into very small cytoarchitectonic fields was rejected (for further discussion, see Mountcastle, 1978).

\subsection{Hippocampal Sectors Resemble Modules}

The hippocampus has a distinctive cytoarchitectonic organization (for recent description see Rosene and Van Hoesen, 1987). The hippocampus proper is divided into sectors CA1, CA2, CA3 and CA4 and is characterized by a narrow band of pyramidal cells. The hippocampal formation includes the hippocampus proper, along with the dentate gyrus and subiculum. Cells in the dentate gyrus and subiculum are less orderly in their arrangement.

The large pyramidal cells and some non-pyramidal cells in the hippocampus proper are cholinoceptive (Woolf, 1993). Like their counterparts in the neocortex, these cholinoceptive cells are MAP-2 rich. Moreover, these hippocampal cells demonstrate enhanced MAP-2 immunoreactivity when ani- mals are trained to remember a novel context (Woolf et al., 1996). Similarly to MAP-2 alterations with tone memory, the MAP-2 changes correlated with contextual memory are confined discrete cytoarchitectonic regions, in this case, hippocampal sectors CA1 and CA2 (Woolf et al., 1996; cf. Woolf et al., 1994).

Since both receive cholinergic afferents from the basal forebrain and both demonstrate restricted cholinoceptive cell plasticity, the cytoarchitecturally defined sectors of the hippocampus proper resemble cortical modules. Affiliated hippocampal regions may also function as relatively discrete units. In this treatise, neocortical modules and hippocampal sectors will be tentatively considered as functionally similar units, tempered by full recognition of their inherent differences. To the extent that this analogy applies, hippocampal sectors might resemble modules of association neocortex (see Pandya and Yeterian, 1985).

\subsection{Amygdalar Nuclei Resemble Modules}

The amygdala is divided into individual nuclei on the basis of cytoarchitecture; these include the basal, basolateral, lateral, cortical, and central nuclei of the amygdala. All parts of the amygdala receive a moderate to dense cholinergic input from the substantia innominata and nucleus basalis (Ch4), except for the central nucleus of the amygdala which may be more sparsely innervated (Woolf, 1991; Amaral and Bassett, 1989). We have observed decreased immunohistochemistry for MAP-2 in the basolateral, lateral, and cortical nuclei of the amygdala with fear conditioning; however, there was some indication of MAP-2 breakdown in the amygdala (Woolf et al., 1994). These findings may indicate that a neural representation for fear was already stored in the amygdala before the animals were trained, because the amygdala is undoubtedly involved in fear conditioning (Maren et al., 1996; Mayford et al., 1996).

The cholinergic cells in the basal forebrain projecting to the amygdala lie immediately lateral to the cholinergic cells projecting to the auditory cortex, and there is potential for dendritic and traditional synaptic contact to exist between these cholinergic cells (see Woolf, 1996b). As shown in Fig. 3, the cholinergic cells might provide the associative link between the frequency-related representation of the tone CS stored in the auditory cortex and the neural representation of the autonomic sensations related to the fear of the US stored in the amygdala.

There is no cortical storage of the association posited. Instead, it is conceived that "associable representations" are stored in the auditory cortex and amygdala. The association requires three neural structures: the auditory cortex, the amygdala, and the cholinergic basal forebrain. Presumably, acetylcholine released from basal forebrain cells causes sequentially focused attention upon these two associable representations; each representation would be selectively attended for approximately one half second corresponding to the firing cycles of cholinergic neurons (for further discussion, see Section 2.1 and Woolf, 1996a). The time frame posited here is 


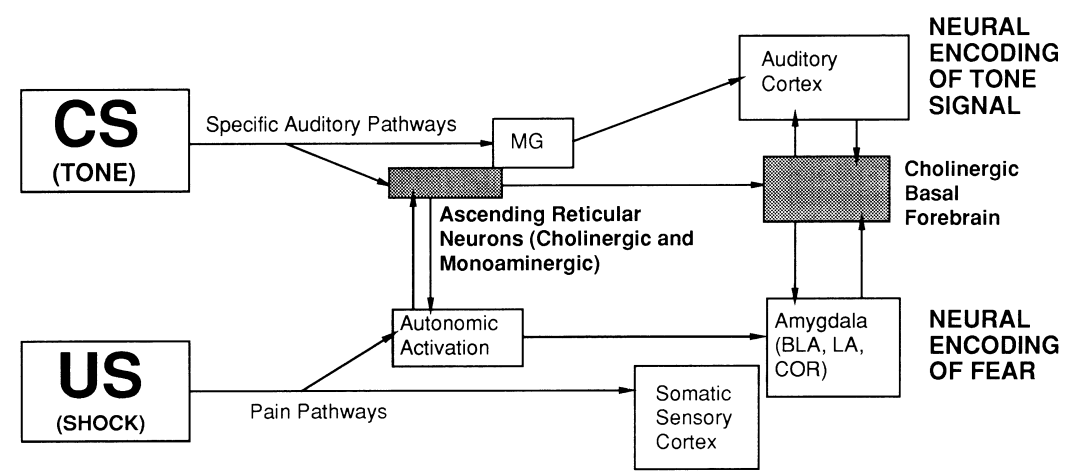

Fig. 3. Scheme of brain regions involved with an association between a tone CS and fear of a shock US. Abbreviations: BLA, basolateral amygdala; COR, cortical nucleus; LA, lateral nucleus; MG, medial geniculate nucleus.

consistent with the long-standing observation that 250-500 msec intervals between the CS and US produce optimal conditioning (McAllister, 1943; McAdam et al., 1965). In this time frame, one associable representation would immediately follow the other; in other words, the two representations would be temporally successive. It follows that the associative strength between two temporally successive representations would be the strongest.

That the association is within limits flexible, such that each associable representation is not strictly tied to its associated partner, is also consistent with the literature on learning preparedness. According to learning preparedness theory, stimulus representations can be associated in many, but not all, possible combinations (for an early review see Seligman, 1970). Also, this proposal is consistent with the literature on reacquisition or spontaneous recovery following extinction. Associations extinguished by unpaired presentations of the CS and US are more easily reestablished with CS-US pairings at a later time (Napier et al., 1992; Rescorla, 1997). Accordingly, associable representations need to be more enduring and associations more flexible. The present model satisfies these requirements-associable representations are encoded by structural changes in dendrites which are enduring associations are due to patterns of acetylcholine release, which are flexible.

All this speculation depends on the ability of the CNS to form associable representations. The next section will be devoted to plausible chemical cascades that may be involved in the formation of associable representations such as those described here in the auditory cortex and amygdala.

\section{HYPOTHETICAL SEQUENCE OF EVENTS SURROUNDING MEMORY ENCODING}

This section deals with possible chemical events during memory encoding of associable representations. The neural correlates of these associable representations are hypothesized to be changes in dendrite segment length and de novo dendrite branch formation. The proposed sequence focuses on the transition from short-term memory to long termmemory.

As illustrated in Fig. 4, the proposed events begin with changes in neuronal activity, then in neurotrophin release, followed by enhanced acetylcholine release, muscarinic response, $\mathrm{Ca}^{2+}$ influx, MAP-2 degradation, and finally new dendrite structure. The latter part of this proposed sequence seems to the same for both the cerebral cortex, for example, auditory association cortex, and the hippocampus, for example, sectors CA1 and CA2 (see Woolf et al., 1994; Woolf et al., 1996). Nonetheless, the time after training at which MAP-2 alterations occur is markedly different for the auditory cortex and hippocampus.

\subsection{Enhanced Electrical Activity}

Increased depolarization or potentiated responses are a likely starting point in the cascade of memory formation, and acetylcholine may play a role. Stimulation of the basal forebrain paired with tone, for example, induces the same kind of receptive field plasticity as does behavioral learning (Bakin and Weinberger, 1996). This is one of the clearest pieces of evidence showing that acetylcholine release is

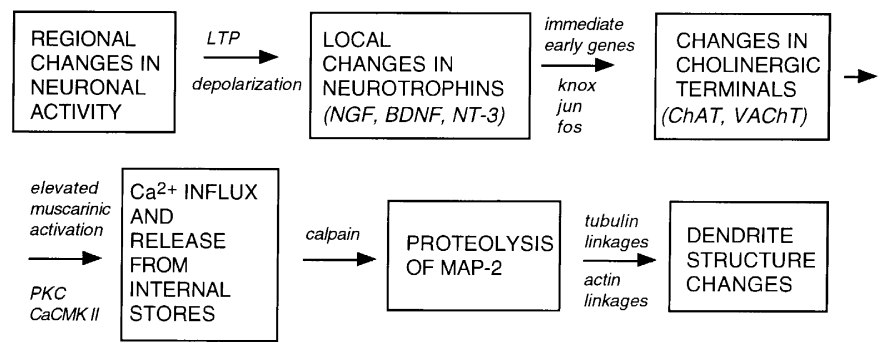

Fig. 4. Hypothetical sequence of molecular events involved in encoding into long-term memory. 
able to initiate the cascade of events leading to memory formation.

Long-term potentiation (LTP) is a putative mechanism that may be operative during memory formation in behaving animals. Recently, LTP has been induced in freely behaving animals by high-frequency stimulation pulsed to mimic the natural theta rhythm (Holscher et al., 1997). A relationship between acetylcholine, theta, and LTP has already been established (Larson and Lynch, 1986; Huerta and Lisman, 1993), but the degree to which acetylcholine participates in LTP exhibited by behaving animals is unknown (see Jerusalinsky et al., 1997). Acetylcholine has been shown to briefly enhance NMDA-dependent LTP, and then induce a specific muscarinic LTP (Segal and Auerbach, 1997). In another report, muscarinic enhancement of NMDA actions is shown to be long-lasting (Aramakis et al., 1997), raising the possibility that acetylcholine may have long-lasting effects on NMDA-dependent LTP in the behaving animal.

\subsection{Induction of Neurotrophins}

There are data suggesting neurotrophins could act as mediators between neuronal activity and morphology. LTP in behaving rats increases BDNF, NT-3, and associated receptors (Bramham et al., 1996). In hippocampal tissue slice, NGF also increases with LTP (Castren et al., 1993). However, it is not necessary to have LTP to elevate neurotrophin levels; depolarization induces NGF and BDNF gene expression (Elliott et al., 1994).

We have recently found increased hippocampal NGF is correlated with contextual memory formation (Milov et al., 1997). Thus, a physiological role for neurotrophins in memory seems apparent. It would appear that NGF may also be necessary for memory acquisition: infusion of antibodies to NGF into the insular cortex produces significant deficits in conditioned taste aversion and avoidance learning (Gutierrez et al., 1997). Previous studies suggest neurotrophins mediate memory processes, as well. NGF, BDNF and NT-3 exert actions on cholinergic basal forebrain neurons, and infusions of these neurotrophins improve memory performance in aged animals (Barde, 1990; Thoenen et al., 1991; Fischer et al., 1994). Exogenously applied neurotrophins may have somewhat different effects on ChAT in the cortex or hippocampus (Winkler and Thal, 1995); however, neurotrophic effects on both septohippocampal and nucleus basalis cells contribute to memory performance (Berger-Sweeney et al., 1994).

Neurotrophins activate the synthesis of proteins through the activation of inducible transcription factors (Segal and Greenberg, 1996). Many immediateearly transcription factors seem to play a role in learning, including those immediate genes in the krox, jun and fos family that are activated by muscarinic receptors (see Dragunow, 1996 for review). Cortical regions showing alterations in morphology with learning also show increases in immediate-early gene expression (Wallace et al., 1995).

\subsection{Changes in Cholinergic Terminals}

The neurotrophins NGF, BDNF and NT-3 increase the production of cholinergic enzymes in cholinergic cells (Friedman et al., 1993; Nonner et al., 1996; Takei et al., 1997). These enzymes include choline acetyltransferase (ChAT) and the vesicular acetylcholine transporter (VAChT). Although high affinity choline uptake is rate limiting to acetylcholine synthesis, it appears that ChAT levels contribute to acetylcholine release more than previously believed (see Collier et al., 1993).

As illustrated in Fig. 5, we have shown that ChAT mRNA is increased selectively in nucleus basalis cells that project to auditory cortex $\mathrm{Te} 2$ when animals are trained to associated a tone CS with fear produced by a shock US (Oh et al., 1996). Neighboring cells in the nucleus basalis projecting to cortical regions other than $\mathrm{Te} 2$ are unaffected. Thus, it would appear that behavioral conditioning initiates a mechanism capable of sustaining enhanced release of acetylcholine.

Finally, there is evidence that associative memory is correlated with increased acetylcholine release; these increases occur only in select cortical regions and only with conditioning and not with habituation (Acquas et al., 1996). Acetylcholine release has also been shown to increase in the hippocampus with a spatial memory task (Fadda et al., 1996).

\subsection{Elevated Muscarinic Receptor Activity}

Given that ChAT mRNA levels are increased (see Oh et al., 1996), sustained release of acetylcholine might be expected to either up-regulate or downregulate muscarinic receptors. In one study evaluating muscarinic receptors after inhibitory avoidance learning, the way in which M1 and M2 muscarinic receptor subtypes were differentially affected in different brain regions was generally indicative of cholinergic activation (Ortega et al., 1996). Van Der Zee and colleagues (1994) also showed enhanced immunohistochemistry for muscarinic receptor in the hippocampus following training, but not after pseudotraining on a spatial discrimination task.

\subsection{Protein Kinase Activation and MAP-2 Phosphorylation}

Muscarinic receptors transduce their signals by activating their coupled G-proteins, which in turn activate many different phospholipases and protein kinases. Many of these signaling cascades lead to the traditional changes in ion channels; however, these signaling cascades may also be involved with neuronal plasticity. Protein kinases that are activated by the muscarinic G-protein complex include: protein kinase $\mathrm{C}(\mathrm{PKC}), \mathrm{Ca}^{+2} /$ calmodulin kinase II, and MAP kinase (Cantrell et al., 1996; Pedarzani and Storm, 1996; Offermanns et al., 1993; Müller et al., 1992; Gutkind et al., 1997); all these kinases are known to phosphorylate MAP-2 (for review see Johnson and Jope, 1992). Thus, muscarinic receptor activation would be expected to enhance MAP-2 phosphorylation, at least in some cases. Muscarinic activation may also lead to the dephosphorylation 

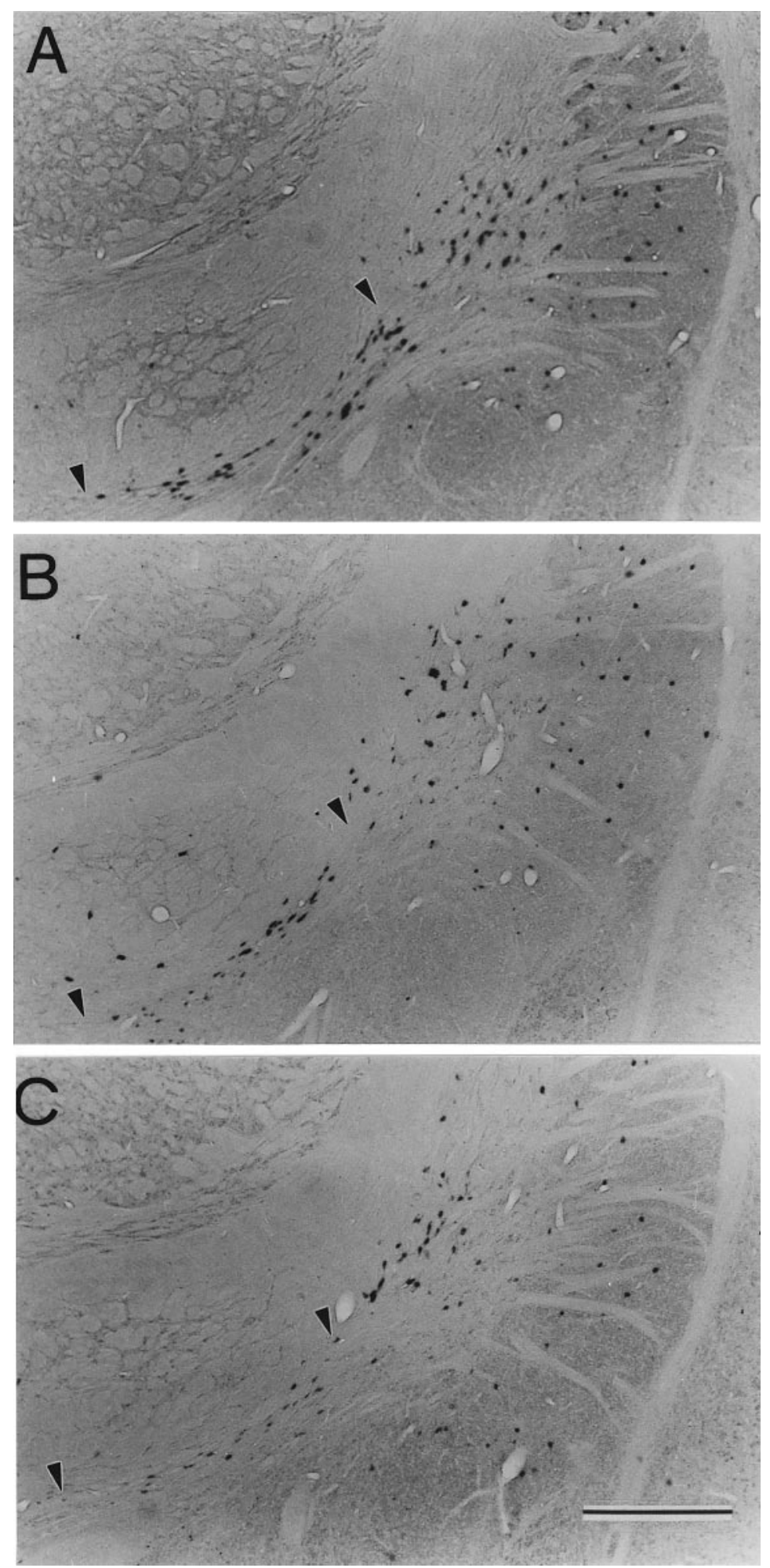

Fig. 5. Photomicrographs showing ChAT mRNA in animals trained with tone paired with shock (A), tone only (B), and tone and shock unpaired. Arrowheads define the ventral half of the nucleus basalis where most cells project to auditory association cortex. Note that cells within these arrowheads are more intensely reactive with probes for ChAT mRNA in trained animals (A) compared to controls (B and C). Slightly modified and reprinted with permission from Oh et al., 1996. Scale bar equals $1 \mathrm{~mm}$. 
of MAP-2, since muscarinic actions include enhancement of NMDA receptor activation (Aramakis et al., 1997, Segal and Auerbach, 1997). Quinlan and Halpain (1996) have shown that, following a brief non-NMDA mediated phosphorylation, MAP-2 is dephosphorylated through NMDA receptor activation.

The role that phosphorylation and dephosphorylation of MAP-2 may play in memory encoding is unclear. Fukunaga and collaborators (1996) suggest that phosphorylation of MAP-2 by $\mathrm{Ca}^{+2} /$ calmodulin kinase II is part of the LTP response. An alternate (or additional) possibility is that changes in the phosphorylation state of MAP-2 regulate dendritic plasticity. Phosphorylation of MAP-2 decreases its co-assembly with microtubules (Diez-Guerra and Avila, 1995; Ainsztein and Purich, 1994; Hoshi et al., 1992; Stofko-Hahn et al., 1992). Thus, phosphorylation of MAP-2 may reduce cytoskeletal stability, thereby favoring dendritic plasticity.

Different isoforms of MAP-2 may be more or less susceptible to phosphorylation and dephosphorylation during memory consolidation. MAP-2 consists of a pair of high molecular mass $(280 \mathrm{kD})$ proteins (isoforms a and b), and a low molecular mass (70 $\mathrm{kD}$ ) polypeptide (isoform c). We have recent evidence compatible with the notion that the low molecular weight MAP-2c may be dephosphorylated following contextual memory training (Woolf et al., 1996).

\subsection{Increased Intracellular $\mathrm{Ca}^{2+}$ and Protease- Mediated Breakdown of MAP-2}

Muscarinic receptor activation increases intracellular $\mathrm{Ca}^{2+}$ through G-protein stimulation of phospholipase $\mathrm{C}$ that activates inositol-P3 inducing $\mathrm{Ca}^{2+}$ release from internal stores (see Siegel et al., 1994). This action may persist at elevated levels during memory formation. Auerbach and Segal (1994) describe a kind of muscarinic LTP that involves increased $\mathrm{Ca}^{2+}$ release from internal stores sequestered in the postsynaptic cell. Muscarinic enhancement of NMDA actions may also lead to increased $\mathrm{Ca}^{2+}$ influx into the postsynaptic cell (Jerusalinsky et al., 1997).

In the cell, $\mathrm{Ca}^{2+}$ activates a number of $\mathrm{Ca}^{2+}$ regulated proteins, some of which are affiliated with plasticity and growth. Neurite growth appears to be mediated by specific $\mathrm{Ca}^{2+}$ channels and $\mathrm{Ca}^{2+}$ released from intracellular stores (Stewart et al., 1995). Of particular relevance to neuronal plasticity and memory, however, is the $\mathrm{Ca}^{2+}$ activated protease, calpain (see Lynch and Baudry, 1984). Calpain degrades the cytoskeletal proteins affiliated with the postsynaptic density; it is especially effective on MAP-2 (Johnson et al., 1991). $\mathrm{Ca}^{2+}$ can be sequestered in dendrite segments or in individual spines (Müller and Connor, 1991), suggesting is may participate in the remodeling of spines or whole dendrite segments.

MAP-2 is also present in spines (Morales and Fifkova, 1989), and its degradation could lead to changes in spine morphology. Changes in spine morphology, however, may be too labile to account for permanent memory encoding. Papa and Segal (1996) found dendritic spines were markedly increased by GABA antagonism; this increase was furthermore dependent on $\mathrm{Ca}^{2+}$ and new protein synthesis. Accordingly, they suggest spine changes are not permanent enough to account for long-term memory. The permanence of spine alterations is debatable; nonetheless, changes in dendrite length and de novo synthesis of dendritic branches are likely to be permanent.

MAP-2 mediation of de novo dendrite branching is likely to occur when MAP-2 is degraded. MAP-2 is normally present in excess amounts in the dendrite, and this prevents new side-branches (Matus et al., 1986). We found MAP-2 degradation occurred in both the cerebral cortex and hippocampus during memory formation (Woolf et al., 1994; Woolf et al., 1996). Accumulated MAP-2 degradation products were shown by enhanced immunohistochemical reaction with antibodies to MAP-2, and this enabled us to identify cells putatively undergoing dendritic restructuring. Many of these cells were the large pyramidal cells with heavily stained apical dendrites. One might predict that the breakdown of MAP-2 allows new side-branches to form, and that this process would involve new protein synthesis. De novo synthesis of MAP-2 occurring in the dendrite is possible: mRNA for MAP-2 is localized within the dendrite (Kleiman et al., 1994). Moreover, cholinergic afferents may trigger synthesis, since protein synthesis increases in hippocampus following combined muscarinic and NMDA receptor stimulation (Feig and Lipton, 1993).

\subsection{Altered Dendritic Structure and Companion Axonal Change}

According to the present hypothetical model, a repository for long-term memory storage is found in the dendritic arbors of cholinoceptive cells of the cerebral cortex, hippocampus, and amygdala. In particular, the dendrites of the large pyramidal cells are implicated as sites of de novo branching resulting from the degradation of MAP-2. The feasibility of this hypothesis is supported by our post-mortem analyses of MAP-2 in animals trained on two memory tasks (Woolf et al., 1994, 1996). Critical verification of altered dendritic branching in these cholinoceptive neurons is not provided by our studies; however, other studies have demonstrated dendritic change in neurochemically unspecified cells, along with increased acetylcholinesterase (for review see Rosenzweig and Bennett, 1996; further discussion in Section 5.1).

At the same time that new dendrites are formed, companion reorganization of cholinergic terminals is postulated. This is highly feasible due to the high degree of plasticity demonstrated by cholinergic terminals. Following axotomy, cholinergic axons reestablish normal innervation patterns in the cerebral cortex (Farris et al., 1993), and NGF modulates the reestablishment of cholinergic fibers and behavioral function recovery (Farris et al., 1995; Tuszynski and Gage, 1995). NGF also increases the number of varicosities, or possible release sites, along the cholinergic axon (Garofalo et al., 1993; Farris et al., 1995). From these results we might speculate that cholinergic axons and their varicos- 
ities rearrange in the appropriate cortical region during memory formation under the guidance of neurotrophins, such as NGF. Alterations in these afferent terminals would affect how much acetylcholine is released and where, of conceivable importance in sensory processing and memory retrieval. Like spine alterations, these axonal alterations are likely to be less permanent than the formation of new dendrite branches.

\section{PREDICTIONS BASED ON THE HYPOTHESIS}

A prediction of this hypothesis is that an associable representation is a permanent long-term memory-defined here as an organized idea that occupies about half a second and is encoded by a set of new dendritic branches. Since terminal branches are added last, new ideas would be represented in the terminal branches. Accordingly, the "idea" of a simple sensory parameter (i.e., a line of a particular orientation) would be encoded by a set of distalmost dendrites in primary sensory cortex, the idea of a shape composed of particularly oriented segments would be encoded by distalmost dendrites in secondary and tertiary cortices, and the most abstract ideas, such as objects and categories, would be encoded by sets of distalmost dendrites in association cortices (see Fig. 6)

Another prediction of this hypothesis is that the ability to retrieve permanently stored memories is mediated altogether differently. Cholinergic activation of the cerebral cortex and hippocampus is one possible means of stimulating these permanently stored memories. Monoaminergic neurotransmitters might accomplish the same (see Introduction). It is furthermore predicted that not only activation per se, but the sequence in which long-term memories are activated would be mediated by these cholinergic and monoaminergic afferent systems.

\subsection{The Structure of Information Storage}

The now classic studies of Rosenzweig, Bennett, Diamond, Greenough, and others were first to show that enriched environments and learning experiences alter cortical dendrites. Brains from animals raised in enriched environments had increased cortical weight, elevated acetylcholinesterase activity, more dendritic spines, and greater dendritic lateral width as compared to animals raised in impoverished environments (Bennett et al., 1969; Rosenzweig et al., 1972; Globus et al., 1973). Since acetylcholinesterase is found in both cholinergic afferent axons and cholinoceptive cells, participation of either or both may be implicated. Greenough and collaborators (1979) more thoroughly explored the possibility of dendritic change and found dendrites of pyramidal cells in the occipital cortex were altered following massed trials of maze training. These dendritic alterations were specific: only distalmost dendritic branches were found to be consistently increased in number and these changes were highly significant.

In studies of the human brain there are also clear indications that memory, experience, and intellectual capacity are correlated with parameters of the distalmost dendritic branches. Coleman and Flood (1986) showed that terminal and next-to-terminal segments, which account for $190 \%$ of the dendritic tree, are most vulnerable to aging-related changes. These segments increase steadily with age, presumably in accordance with increased experience due to age, and then decline significantly with senile dementia. More proximal dendrites do not show these changes. Thus, we see a correspondence between experience and intellectual capacity selectively in these distalmost dendrites. This relationship is demonstrated in other studies. In a series of papers from the Scheibel laboratory, distal dendrites prove to be a sensitive marker of higher cognitive function. Distal dendrite segments were longer than proximal segments in association cortices related to speech as compared to the relationships found in motor cortex, and dendritic parameters were increased in the left hemisphere as compared to the right (Jacobs et al., 1993a,b). Moreover, educational level corresponded with dendritic length of 3rd and 4th order dendrites (Jacobs et al., 1993b). In contrast to Coleman and Flood (1986), Jacobs and Scheibel (1993) found decreasing dendritic parameters in the parahippocampal gyrus with age. Different brain regions were evaluated in

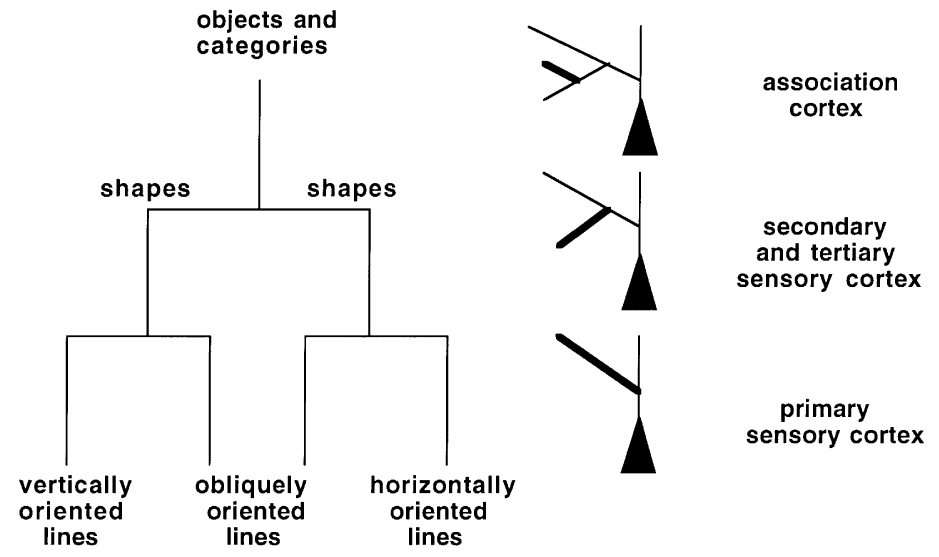

Fig. 6. Proposed storage sites for information of varying complexities in distal dendrites of pyramidal cells of different cortical areas. 
the two studies that might account for the different outcomes, however.

The current notion of an associable representation has many features in common with a moment of consciousness (see Woolf, 1997). In this regard, the quantum coherence theory of microtubules may be relevant. Hameroff and Penrose (1995) have hypothesized that the collapse of a coherent resonance involving $1 \%$ of the tubulin molecules in assemblies of 10000 neurons could account for a conscious thought lasting one half second. Coherence of microtubules is unlike anything previously described in neurobiology. It involves a high frequency resonance among the water molecules associated with tubulin dimers of microtubules. This resonance induces a state of self-induced transparency within the inner core of the microtubular lattice, enabling a high energy form to radiate down the microtubule like a laser (Jibu et al., 1994).

Cholinergic afferents might trigger microtubular coherence and self-collapse via muscarinic affects on MAP-2 phosphorylation (Woolf, 1997). This is possible, because the position of MAP-2 binding sites to microtubules affects the timing of coherence and self-collapse (see Hameroff and Penrose, 1995) and phosphorylation of MAP-2 decreases binding with microtubules (Hoshi et al., 1992; Stofko-Hahn et al.,
1992; Ainsztein and Purich, 1994; Diez-Guerra and Avila, 1995). Accordingly, brief changes in MAP-2 binding to microtubules located near muscarinic synapses would be expected to affect microtubular coherence and self-collapse.

Microtubular coherence among sets of distalmost dendrites is a plausible mechanism for markedly distinguishing an associable representation against a background of noisy brain activity - an activation that is far more precise than mere stimulation by a neurotransmitter. A possible underlying physical substrate for determining the collective of dendrite segments that will engage in this process at any one time might be related to the infrastructure of the microtubules in those dendrite segments. Coherence might be expected to occur in sets of dendrite segments sharing a similar microtubular infrastructure, for example, the same specific spacing intervals between MAP-2 binding sites to microtubules (Woolf, 1997). The chemical cascades described in the present paper would be capable of simultaneously constructing dendrite segments in multiple cholinoceptive cells, and it is conceivable that dendrites made at the same time may have similar infrastructures.

As shown in Fig. 7A, a set of similarly structured distalmost dendrites originating from cholinoceptive

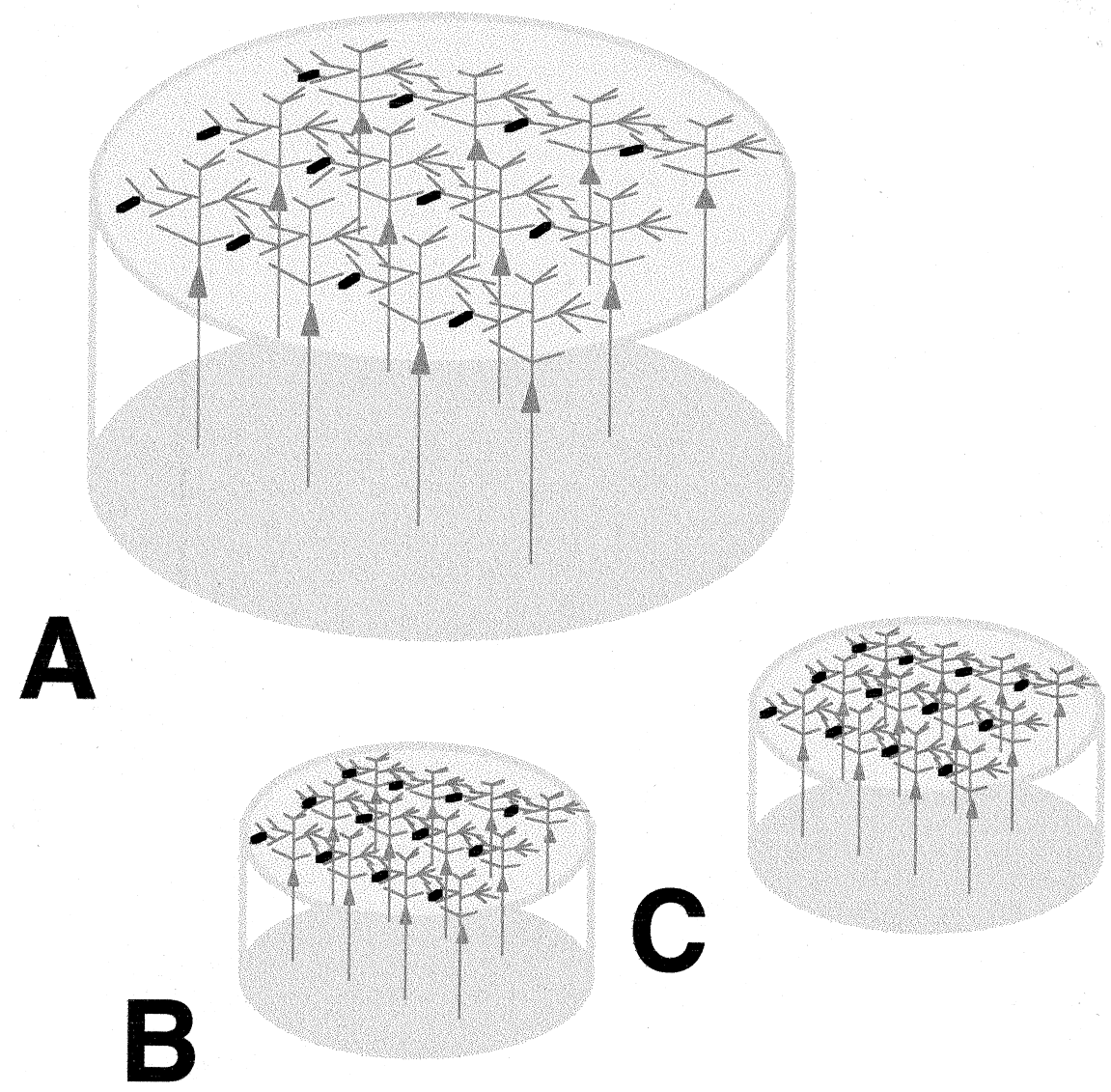

Fig. 7. Hypothetical scheme for an associable representation stored in select distal dendrites (thick lines) of multiple cholinoceptive cells distributed throughout one module (A) with the possible participation of simultaneous activation of distal dendrites in additional modules (B and $\mathrm{C}$ ). 
cells dispersed throughout a module of association cortex could encode a higher-order associable representation. Subordinate components of the associable representation might be stored in other modules (see Fig. 7B and C). Just as sets of dendrites within a module might be formed with similar infrastructures, dendrites across modules might be formed that share a common infrastructure. In these instances, we might expect structural correspondences to exist between the more proximal dendrites of association areas and the more distal dendrites of primary and secondary cortices (see Fig. 6), because dendrites in primary sensory cortex finish developing much earlier than do dendrites in higher association cortex (Garey, 1984 cf. Mrzljak et al., 1990). During memory retrieval, the entire ensemble might be coactivated momentarily both by neurobiological processes such as acetylcholine release and by other phenomena such as microtubular coherence.

Another prediction derived from the present hypothetical model is that the brain encodes basic sensory parameters in a similar manner to how it encodes complex ideas. Orientation specificity might be encoded as an associable representation through cholinergic modulation of dendrite structure in modules of primary visual cortex. In particular, the laterally ramifying basilar dendrites of pyramidal cells are likely participants. For one, there are indications that laterally projecting dendrites containing MAP-2 are involved with visual plasticity (Reid and Daw, 1995). Also, a specific transcription factor, Zif268 is found in pyramidal cells that contain MAP-2 and this transcriptional factor is altered by activity in the visual pathway (Chaudhuri et al., 1995).

Modules of visual cortex contain orientationspecific pinwheels that radiate from a central zone that displays no orientation specificity (see Bartfeld and Grinvald, 1992). This arrangement is compatible with the present model, particularly if we focus our attention on the largest pyramidal cells. The Meynert cells are conceivably the largest pyramidal cells in primary visual cortex and these cells possess basilar dendrites that generally extend $0.2 \mathrm{~mm}$ in the lateral direction, but can occasionally extend as much as $0.6 \mathrm{~mm}$ (Winfield et al., 1983). The reason orientation specificity may be dictated by the direction of these large dendrites is that within that radial sector more tubulin molecules would be oriented in that direction than in any other. Both Meynert cells and pinwheel centers lie outside cytochrome oxidase-rich blobs (Payne and Peters, 1989; Bartfeld and Grinvald, 1992), indicating they may overlap. Smaller pyramidal cells and their dendrites lie both inside and outside cytochrome oxidase patches (Hubener and Bolz, 1992; Malach, 1992), suggesting that they are less likely to contribute to the pinwheel architecture.

The basilar dendrite arbors of Meynert cells are not symmetric as one might expect; their shapes are elliptical with the long axis oriented in parallel with the horizontal meridian and the ocular dominance bands (Winfield et al., 1983). Is it conceivable that this shape is related to orientation specificity? It seems that some dendrites may grow in a specific direction due to orientation specific responses. In dark-reared kittens exposed only to vertical lines, dendrites of pyramidal cells, but not those of sellate cells, preferentially grew in the direction orthogonal to the representation of the vertical meridian; selective exposure to horizontal stimuli produced dendrites that follow a direction parallel with the representation of the vertical meridian (Tieman and Hirsch, 1982). Also, the first cholinergic axons to develop in dark-reared kittens only exposed to either vertical or horizontal lines lie orthogonal or parallel, respectively, to the representation of the vertical meridian (Woolf, 1992). Thus, for certain cells in the visual cortex, it appears that exposure to orientation specific stimuli affects the morphology of dendrites; also, the cholinergic axons in the visual cortex respond to specifically oriented stimuli.

A number of findings generated in the 1980s support the general notion that both MAP-2 and acetylcholine mediate plasticity in the visual cortex. Aoki and Siekevitz (1985) showed that phosphorylation of MAP-2 is essential for visual plasticity: samples of visual cortex from dark-reared kittens underwent a high degree of phosphorylation in vitro, due to the fact that the protein was not fully phosphorylated in vivo. Bear and Singer (1986) showed cholinergic and noradrenergic afferents to the visual cortex were essential for visual plasticity: changes in response that usually occur after monocular occlusion were inhibited by combined destruction of cholinergic and noradrenergic inputs. More recently, it has been shown that this plasticity depends on M1 muscarinic receptors (Gu and Singer, 1993).

The postulated cholinergic mediation of microtubular coherence in dendrites of visual cortex accounting for orientation-specific responses offers a new perspective that might prompt novel lines of investigation. For example, one might want to compare the pinwheel architecture with the topography of the Meynert cell dendrites.

The proposed general structure for long-term memory encoding may also be of heuristic value. For example, it enables some predictions about memory capacity and aging-related disorders of memory.

\subsection{Memory Capacity: Infinite or Finite?}

The current model is sufficiently detailed to make predictions about memory capacity. Long-term memory capacity would be limited by the number of distal dendrites of individual pyramidal multiplied by the number of modules in the cerebral cortex and hippocampus. Distal dendrite counts made in serially reconstructed neurons of hippocampus indicate each pyramidal cell has approximately 80 terminal dendrites (Ishizuka et al., 1995). Mountcastle (1978) estimates that there are approximately 600000 modules in the cerebral cortex - not including limbic system modules. This gives us a conservative estimate of a capacity able to hold approximately 50 million individual associable representations stored in longterm memory - each encoded by ensembles of distal dendrites emanating from approximately 500015000 large pyramidal cholinoceptive cells organized within one to three restricted modules of cerebral cortex or hippocampus.

Are 50 million associable representations stored in long-term memory a reasonable estimate? A 100- 
year lifetime consists of 3 billion seconds or 6 billion half second slots available within which to store a new associable representation in long-term memory. Thus, this capacity would not be reached in a 100year lifetime, even if one formed new memories at a rate of one per minute. This is consistent with reports that, in the absence of neurobiological disease, the accumulation of knowledge which is also referred to as crystallized intelligence, increases with age (Horn and Noll, 1997).

Theoretically, retrieval of items from long-term memory should be limitless. Cholinergic and monoaminergic systems should be able to retrieve information countless times and in countless combinations. This is what would be predicted if there were no biological changes in the neurons. Unfortunately, there are cellular changes that target both cholinergic and cholinoceptive neurons, and thus, there are declines in cognitive abilities due to aging, as well as more dramatic deterioration due to aging-related disorders such as Alzheimer's disease. We will discuss these issues next.

\subsection{Memory Storage and Aging}

What does a long-term memory capacity that is theoretically so large tell us about normal aging or Alzheimer's disease? It might cause us to question why intellectual ability deteriorates with Alzheimer's disease, sometimes even in the early stages (see Newman et al., 1994). Since there seem to be enough dendrites on cholinoceptive neurons to store many, many associable representations in long term-memory, the problem may be that the same brain regions are used over and over again for memory storage. The frontal cortex, for example, is a region containing higher-order association areas. Neuropathological entities - senile plaques and neurofibrillary tangles - were occasionally found in the superior frontal cortex of persons aged 96-102 years regardless of whether or not they showed signs of dementia (Giannakopoulos et al., 1993). What did distinguish the brains of these very old persons were dense concentrations of neurofibrillary tangles in the hippocampus - especially in CAl-found only in those with Alzheimer's dementia (Giannakopoulos et al., 1993). A relative lack of neurofibrillary tangles in most brain regions of those approximately 100 years of age without dementia is quite remarkable and supports the estimate made in this paper that dendritic memory capacity is very large.

Centenarians, however, are unusual in their lack of hippocampal and cortical deterioration. In two studies sampling a large population of subjects, the density of neurofibrillary tangles in entorhinal cortex and CA1 of hippocampus increased with age for both demented and non-demented subjects, even though the pathology was much greater in the demented subjects (Bouras et al., 1994; Giannakopoulos et al., 1994). Senile plaques were found in both demented and non-demented groups; nonetheless, neurofibrillary tangles were present in frontal and occipital cortex only in demented subjects (Bouras et al., 1994; Giannakopoulos et al., 1994). We can make a few conclusions from these results. Although the cortical system is capable of a lifetime of use without deterioration as evidenced by the paucity of neuropathology in many centenarians, most individuals experience cortical deterioration, especially in hippocampus, with normal aging and severe deterioration if afflicted with Alzheimer's disease. In addition to neurofibrillary tangles, degenerative damage occurs selectively in distal dendrites of hippocampal pyramidal cells (Braak and Braak, 1997), the site proposed for new memory storage.

Most cells developing neurofibrillary tangles appear to be cholinoceptive. Morrison and colleagues (1987) showed cortical neurons that develop neurofibrillary tangles are immunoreactive to antibodies against non-phosphorylated neurofilament. Neurons demonstrated to be cholinoceptive on the basis of acetylcholinesterase activity are also immunoreactive to antibodies against non-phosphorylated neurofilament; however, acetylcholinesterase containing cells in the underlying white matter are not (Mesulam and Geula, 1991). Comparisons restricted to the gray matter show that $84 \%$ of neurofilament-rich cells (and $80 \%$ of MAP-2 cells) are immunoreactive to antibodies against muscarinic receptor (Woolf, 1993). Even though cholinoceptive cells would appear to be vulnerable to neurofibrillary tangle formation, there is no obligatory relationship - neurons do not develop tangles merely because they are cholinoceptive (Mesulam et al., 1994).

A prediction based on the current proposal is that neurofibrillary tangles form in cholinoceptive neurons that have participated in repeated and extensive restructuring due to encoding associable representations in long-term memory (also see Woolf and Butcher, 1990). CA1 of hippocampus, which develops dense accumulations of neurofibrillary tangles in Alzheimer's disease, is an area of the brain that appears to be involved in many types of memory (Rotenberg et al., 1996; Ishikawa et al., 1997; Ridley and Baker, 1997). In our memory experiments with rodents, MAP-2 degradation related to contextual memory occurred in CA1 of hippocampus 2 weeks after training. It is conceivable that enhanced acetylcholine release and cholinergic axon reorganization ongoing during the 2-week period following training, contributes to hippocampal cell vulnerability.

Since cholinergic afferent axons must "search out" by means of guided axonal growth suitable dendritic segments for memory encoding, it follows that as more and more dendritic segments become dedicated to other associable representations stored in long-term memory, intensified axonal growth may damage the parent cholinergic cell and also interfere with the functioning of other cholinergic neurons. Arendt and colleagues (1994) have studied changes in cholinergic neurons in Alzheimer's disease and have determined that these basal forebrain neurons are vulnerable to neuropathology and cell death because of their pluripotence and potential for plasticity. That cholinergic cell death could be due to intensified axonal growth is consistent with cholinergic cell loss being most severe in regions of the basal forebrain that project to cortical regions containing the most neuropathology (see Arendt et al., 1985). In addition to cell death of basal forebrain neurons, neuropathology also develops in the 
basal forebrain with Alzheimer's disease. Neuropathology in the basal forebrain seems to be highly correlated with scores on tests for memory ability, whereas loss of cortical synapses was strongly correlated with scores on tests for cognitive ability (Samuel et al., 1994). Neuropathology in the cholinergic basal forebrain precedes cortical volume loss and cholinergic cell loss, suggesting that changes to cholinergic neurons are a primary event (Cullen et al., 1997).

It remains a mystery why cholinergic therapy is not more effective in ameliorating memory problems in Alzheimer's disease problems (see Decker, 1995; Gualtieri et al., 1995); however, cholinergic therapy might be more effective if memory encoding and retrieval could be selectively enhanced, without stimulating axon and dendrite reorganization in severely damaged areas. Inhibitors of neuronal growth used in combination with cholinergic agonists has been suggested (Woolf and Butcher, 1990). Another viable approach might be to stimulate cholinergic function in the neocortex to take over mnemonic function from the severely impaired hippocampus. This could work, if, as suggested, the hippocampal sectors are to a large extent functionally equivalent to modules of association neocortex.

There is indication that the neocortex can mediate learning acquisition in the absence of the hippocampus, provided that the entire limbic circuitry is completely removed. Much to the surprise of the investigators of these studies, mnemonic function was unimpaired with lesions of the entire limbic system-which included the hippocampus and septum - in marked contrast to learning impairments resulting when the hippocampus or other individual limbic structures were damaged singly or in pairs (Irle, 1985; Irle and Markowitsch, 1990).

Obviously, damaged circuitry cannot be removed from Alzheimer's disease patients, but perhaps this paradigm might be duplicated pharmacologically: either through muscarinic agonists that are regionally selectively for the neocortex or muscarinic antagonists that are regionally selective for the hippocampus and limbic system. The latter suggestion, using cholinergic antagonism to increase functions mediated by cortical acetylcholine seems counterintuitive on the surface. However, cholinergic antagonism in one part of the brain may indeed increase cholinergic functional capacity in another part of the brain, since attention to one task mediated by acetylcholine is constrained by attention to other competing tasks (see Callaway et al., 1992).

Regionally selective pharmacological agents, to the extent that they are possible to make, might be used alone or in combination with inhibitors of oxidative damage and unproductive neural growth. The aim being to preserve memory ability, as well as to decrease the progression of neuropathological degeneration.

\section{CONCLUSIONS}

A model has been presented for dendrite reorganization in cholinoceptive cells of the telencephalon as the basis for long-term memory storage. A precise molecular sequence was proposed. Implications that the model has for memory capacity and memory disorders were also discussed. Perhaps the best test of the model would be high-resolution imaging of microtubule coherence or some related phenomenon, if and when such imaging techniques become available. Other approaches might be applied more readily. The molecular sequence proposed in longterm memory storage might be tested with protein inhibitors, genetic knock-out mice, or gene knockdown experiments. The hope is that rather than looking to a single molecule an emphasis on sequences of events becomes more prevalent in research concerning the neurobiology of memory.

\section{REFERENCES}

Acquas, E., Wilson, C. and Fibiger, H. C. (1996) Conditioned and unconditioned stimuli increase frontal cortical and hippocampal acetylcholine release: effects of novelty, habituation, and fear. $J$. Neurosci. 16, 89-96.

Ainsztein, A M and Purich, D L (1994) Stimulation of tubulin polymerization by MAP-2. Control protein kinase C-mediated phosphorylation at specific sites in the microtubule-binding region. J. Biol. Chem. 269, 28465-28471.

Amaral, D. G. and Bassett, J. L. (1989) Cholinergic innervation of the monkey amygdala: an immunohistochemical analysis with antisera to choline acetyltransferase. J. comp. Neurol. 281, 337361

Aoki, C. and Siekevitz, P. (1985) Ontogenetic changes in the cyclic adenosine $3^{\prime}, 5^{\prime}$-monophosphate-stimulatable phosphorylation of cat visual cortex proteins, particularly of microtubule-associated protein 2 (MAP 2): effects of normal and dark rearing and of the exposure to light. J. Neurosci. 5, 2465-2483.

Aramakis, V. B., Bandrowski, A. E. and Ashe, J. H. (1997) Activation of muscarinic receptors modulates NMDA receptormediated responses in auditory cortex. Exp. Brain Res. 113, 484-496.

Arendt, T., Bigl, V., Tennstedt, A. and Arendt, A. (1985) Neuronal loss in different parts of the nucleus basalis is related to neuritic plaque formation in cortical target areas in Alzheimer's disease. Neuroscience 14, 1-14.

Arendt, T., Bruckner, M. K., Bigl, V. and Marcova, L. (1994) Dendritic reorganisation in the basal forebrain under degenerative conditions and its defects in Alzheimer's disease. III. The basal forebrain compared with other subcortical areas. J. comp. Neurol. 351, 223-246.

Auerbach, J. M. and Segal, M. (1994) A novel cholinergic induction of long-term potentiation in rat hippocampus. $J$ Neurophysiol. 72, 2034-2040.

Baddeley, A. D. (1992) Memory theory and memory therapy. In: Clinical management of memory problems, 2nd ed, pp. 1-31. Eds B. A. Wilson, N. Moffat. Singular Publishing Group, Inc: San Diego, CA, US

Bakin, J. S. and Weinberger, N. M. (1996) Induction of a physiological memory in the cerebral cortex by stimulation of the nucleus basalis. PNAS 93, 11219-11224.

Barde, Y. A. (1990) The nerve growth factor family. Prog. Growth Factor Res. 4, 237-248.

Bartfeld, E and Grinvald, A. (1992) Relationships between orientation-preference pinwheels, cytochrome oxidase blobs, and ocular-dominance columns in primate striate cortex. PNAS 89, 11905-11909.

Bartolini, L., Risaliti, R. and Pepeu, G. (1992) Effect of scopolamine and nootropic drugs on rewarded alternation in a T-maze. Pharm. Biochem. Behav. 43, 1161-1164.

Bartus, R. T., Dean, R. L., III, Beer, B. and Lippa, A. S. (1982) The cholinergic hypothesis of geriatric memory dysfunction. Science 217, 408-414.

Baxter, M. G., Bucci, D. J., Sobel, T. J., Williams, M. J., Gorman, L. K. and Gallagher, M. (1996) Intact spatial learning following lesions of basal forebrain cholinergic neurons. Neuroreport 7, 1417-1420.

Bear, M. F. and Singer, W. (1986) Modulation of visual cortical plasticity by acetylcholine and noradrenaline. Nature 320, 172176. 
Beatty, W. W. and Bierley, R. A. (1986) Scopolamine impairs encoding and retrieval of spatial working memory in rats. Physiol. Psych. 14, 82-86.

Bennett, E. L., Rosenzweig, M. R. and Diamond, M. C. (1969) Rat brain: Effects of environmental enrichment on wet and dry weights. Science 163, 825-826.

Berger-Sweeney, J., Heckers, S., Mesulam, M.-M., Wiley, R. G., Lappi, D. A. and Sharma, M. (1994) Differential effects on spatial navigation of immunotoxin-induced cholinergic lesions of the medial septal area and nucleus basalis magnocellularis. $J$. Neurosci. 14, 4507-4519.

Bigl, V., Woolf, N. J. and Butcher, L. L. (1982) Cholinergic projections from the basal forebrain to frontal, parietal, temporal, occipital, and cingulate cortices: a combined flourescent tracer and acetylcholinesterase analysis. Brain Res. Bull. 8, 727-749.

Blokland, A. (1995) Acetylcholine: a neurotransmitter for learning and memory? Brain Res. Rev. 21, 285-300.

Boissiere, F., Faucheux, B., Ruberg, M., Agid, Y. and Hirsch, E. C. (1997) Decreased TrkA gene expression in cholinergic neurons of the striatum and basal forebrain of patients with Alzheimer's disease. Exp. Neurol. 145, 245-252.

Bouras, C., Hof, P. R., Giannakopoulos, P., Michel, J. P. and Morrison, J. H. (1994) Regional distribution of neurofibrillary tangles and senile plaques in the cerebral cortex of elderly patients: a quantitative evaluation of a one-year autopsy population from a geriatric hospital. Cerebral Cortex 4, 138-150.

Bowen, D. M., Smith, C. B., White, P. and Davison, A. N. (1976) Neurotransmitter-related enzymes and indices of hypoxia in senile dementia and other abiotrophies. Brain 99, 459-496.

Braak, E. and Braak, H. (1997) Alzheimer's disease: transiently developing dendritic changes in pyramidal cells of sector CA1 of the Ammon's horn. Acta Neuropathologica 93, 323-325.

Bramham, C. R., Southard, T., Sarvey, J. M., Herkenham, M. and Brady, L. S. (1996) Unilateral LTP triggers bilateral increases in hippocampal neurotrophin and trk receptor mRNA expression in behaving rats: evidence for interhemispheric communication. J. comp. Neurol. 368, 371-382.

Brion, J. P. (1996) The neurobiology of Alzheimer's disease. Acta Clinica Belgica 51, 80-90.

Cajal, S. R. (1928) Degeneration and Regeneration of the Nervous System. Oxford University Press: London.

Callaway, E., Halliday, R. and Naylor, H. (1992) Cholinergic activity and constraints on information processing. Biol. Psych. 33, $1-22$.

Cantrell, A. R., Ma, J. Y., Scheuer, T. and Catterall, W. A. (1996) Muscarinic modulation of sodium current by activation of protein kinase $\mathrm{C}$ in rat hippocampal neurons. Neuron 16, 10191026.

Castren, E., Pitkanen, M., Sirvio, J., Parsadanian, A., Lindholm, D., Thoenen, H. and Riekkinen, P. J. (1993) The induction of LTP increases BDNF and NGF mRNA but decreases NT-3 mRNA in the dentate gyrus. Neuroreport 4, 895-898.

Chaudhuri, A., Matsubara, J. A. and Cynader, M. S. (1995) Neuronal activity in primate visual cortex assessed by immunostaining for the transcription factor Zif268. Visual Neurosci. 12, $35-50$

Cheal, M. L. (1981) Scopolamine disrupts maintenance of attention rather than memory processes. Behav. Neur. Biol. 33, 163187.

Coleman, P. D. and Flood, D. G. (1986) Dendritic proliferation in the aging brain as a compensatory repair mechanism. Prog. Brain Res. 70, 227-237.

Collier, B., Tandon, A., Prado, M. A. M. and Bachoo, M. (1993) Storage and release of acetylcholine in a sympathetic ganglion. Prog. Brain Res. 98, 265-284.

Cowan, N. (1995) Attention and memory: An integrated framework. Oxford University Press: New York, NY, US

Cullen, K. M., Halliday, G. M., Double, K. L., Brooks, W. S., Creasey, H. and Broe, G. A. (1997) Cell loss in the nucleus basalis is related to regional cortical atrophy in Alzheimer's disease. Neuroscience 78, 641-652.

Decker, M. W. (1995) Animal models of cognitive function. Crit. Rev. Neurobiol. 9, 321-343.

Diez-Guerra, F. J. and Avila, J. (1995) An increase in phosphorylation of microtubule-associated protein 2 accompanies dendrite extension during differentiation of cultured hippocampal neurones. Eur. J. Biochem. 227, 68-77.

Dornan, W. A., McCampbell, A. R., Tinkler, G. P., Hickman, L. J., Bannon, A. W., Decker, M. W. and Gunther, K. L. (1996) Comparison of site-specific injections into the basal forebrain on water maze and radial arm maze performance in the male rat after immunolesioning with $192 \mathrm{IgG}$ saporin. Behav. Brain Res. 82, 93-101.

Drachman, D. A. (1977) Memory and cognitive function in man: does the cholinergic system have a specific role? Neurology 27, 783-790.

Dragunow, M. (1996) A role for immediate-early transcription factors in learning and memory. Behavior Genetics 26, 293-299.

Elliott, R. C., Inturrisi, C. E., Black, I. B. and Dreyfus, C. F. (1994) An improved method detects differential NGF and BDNF gene expression in response to depolarization in cultured hippocampal neurons. Mol. Brain Res. 26, 81-88.

Fadda, F., Melis, F. and Stancampiano, R. (1996) Increased hippocampal acetylcholine release during a working memory task. Eur. J. Pharmacol. 307, R1-2.

Farris, T. W., Butcher, L. L., Oh, J. D. and Woolf, N. J. (1995) Trophic-factor modulation of cortical acetylcholinesterase reappearance following transection of the medial cholinergic pathway in the adult rat. Exp. Neurol. 131, 180-192.

Farris, T. W., Woolf, N. J., Oh, J. D. and Butcher, L. L. (1993) Reestablishment of laminar patterns of cortical acetylcholinesterase activity following axotomy of the medial cholinergic pathway in the adult rat. Exp. Neurol. 121, 77-92.

Feig, S. and Lipton, P. (1993) Pairing the cholinergic agonist carbachol with patterned Schaffer collateral stimulation initiates protein synthesis in hippocampal $\mathrm{CA}_{1}$ pyramidal cell dendrites via a muscarnic, NMDA-dependent mechanism. J. Neurosci. 13, 1010-1021.

Fischer, W., Sirevaag, A., Wiegand, S. J., Lindsay, R. M. and Bjorklund, A. (1994) Reversal of spatial memory impairments in aged rats by nerve growth factor and neurotrophins 3 and 4 / 5 but not by brain-derived neurotrophic factor. PNAS 91, $8607-8611$.

Friedman, W. J., Ibanez, C. F., Hallbook, F., Persson, H., Cain, L. D., Dreyfus, C. F. and Black, I. B. (1993) Differential actions of neurotrophins in the locus coeruleus and basal forebrain. Exp. Neurol. 119, 72-78.

Fukunaga, K., Muller, D. and Miyamoto, E. (1996) CaM kinase II in long-term potentiation. Neurochem. Int. 28, 343-358.

Garey, L. J. (1984) Structural development of the visual system of man. Human Neurobiol. 3, 75-80.

Garofalo, L., Ribeiro-da-Silva, A. and Cuello, A. C. (1993) Potentiation of nerve growth factor-induced alterations in cholinergic fibre length and presynaptic terminal size in cortex of lesioned rats by the monosialoganglioside GM1. Neuroscience 57, 21-40.

Giannakopoulos, P., Hof, P. R., Mottierm, S., Michel, J. P. and Bouras, C. (1994) Neuropathological changes in the cerebral cortex of 1258 cases from a geriatric hospital: retrospective clinicopathological evaluation of a 10-year autopsy population. Acta Neuropathologica 87, 456-468.

Giannakopoulos, P., Hof, P. R., Surini, M., Michel, J. P. and Bouras, C. (1993) Quantitative immunohistochemical analysis of the distribution of neurofibrillary tangles and senile plaques in the cerebral cortex of nonagenarians and centenarians. Acta Neuropathologica $\mathbf{8 5}, 602-610$.

Givens, B. and Olton, D. S. (1994) Local modulation of basal forebrain: effects on working and reference memory. $J$. Neurosci. 14, 3578-3587.

Globus, A., Rosenzweig, M. R., Bennett, E. L. and Diamond, M. C. (1973) Effects of differential experience on dendritic spine counts in rat cerebral cortex. J. comp. physiol. Psych. 82, 175181

Greenough, W. T., Juraska, J. M. and Volkmar, F. R. (1979) Maze training effects on dendritic branching in occipital cortex of adult rats. Behav. Neural. Biol. 26, 287-297.

$\mathrm{Gu}$, Q. and Singer, W. (1993) Effects of intracortical infusion of anticholinergic drugs on neuronal plasticity in kitten striate cortex. Eur. J. Neurosci. 5, 475-485.

Gualtieri, F., Dei, S., Manetti, D., Romanelli, M. N., Scapecchi, S. and Teodori, E. (1995) The medicinal chemistry of Alzheimer's and Alzheimer-like diseases with emphasis on the cholinergic hypothesis. Farmaco 50, 489-503.

Gutierrez, H., Miranda, M. I. and Bermudez-Rattoni, F. (1997) Learning impairment and cholinergic deafferentation after cortical nerve growth factor deprivation. J. Neurosci. 17, 3796-3803.

Gutkind, J. S., Crespo, P., Xu, N., Teramoto, H. and Coso, O. A. (1997) The pathway connecting $\mathrm{m}_{2}$ receptors to the nucleus involves small GTP-binding proteins acting on divergent MAP kinase cascades. Life Sci 60, 999-1006.

Hameroff, S. and Penrose, R. (1995) Orchestrated reduction of quantum coherence in brain microtubules: a model for consciousness. In Scale in Conscious Experience: Is the Brain Too 
Important to be Left to Specialists to Study? pp. 243-274, Eds J. King and K. H. Pribram. Lawrence Erlbaum Associates: Mahwah, NJ.

Hasselmo, M. E., Wyble, B. P. and Wallenstein, G. V. (1996) Encoding and retrieval of episodic memories: role of cholinergic and GABAergic modulation in the hippocampus. Hippocampus 6, 693-708.

Hebb, D. O. (1949) Organization of Behavior: A Neuropsychological Theory. Wiley: New York.

Heckers, S., Ohtake, T., Wiley, R. G., Lappi, D. A., Geula, C. and Mesulam, M.-M. (1994) Complete and selective cholinergic denervation of rat neocortex and hippocampus but not amygdala by an immunotoxin against the p75 NGF receptor. $J$. Neurosci. 14, 1271-1289.

Hersi, A. I., Rowe, W., Gaudreau, P. and Quirion, R. (1995) Dopamine D1 receptor ligands modulate cognitive performance and hippocampal acetylcholine release in memory-impaired aged rats. Neuroscience 69, 1067-1074.

Holscher, C., Anwyl, R. and Rowan, M. J. (1997) Stimulation on the positive phase of hippocampal theta rhythm induces longterm potentiation that can be depotentiated by stimulation on the negative phase in area CAl in vivo. J. Neurosci. 17, 64706477

Horn, J. L. and Noll, J. (1997) Human cognitive capabilities: GfGc theory. In: Contemporary Intellectual Assessment, pp. 53-91, Eds D. P. Flanagan, J. L. Genshaft, P. L. Harrison. Guilford Press: New York, NY.

Hoshi, M., Ohta, K., Gotoh, Y., Mori, A., Murofushi, H., Sakai, H. and Nishida, E. (1992) Mitogen-activated-protein-kinase-catalyzed phosphorylation of microtubule-associated proteins, microtubule-associated protein 2 and microtubule-associated 4 , induces an alteration in their function. Eur. J. Biochem. 203, $43-52$.

Hubener, M. and Bolz, J. (1992) Relationships between dendritic morphology and cytochrome oxidase compartments in monkey striate cortex. J. comp. Neurol. 324, 67-80.

Huerta, P. T. and Lisman, J. E. (1993) Heightened synaptic plasticity of hippocampal CA1 neurons during a cholinergically induced rhythmic state. Nature 364, 723-725.

Irle, E. (1985) Combined lesions of septum, amygdala, hippocampus, anterior thalamus, mamillary bodies and cingulate and subicular cortex fail to impair the acquisition of complex learning tasks. Exp. Brain Res. 58, 346-361.

Irle, E. and Markowitsch, H. J. (1990) Functional recovery after limbic lesions in monkeys. Brain Res. Bull. 25, 79-92.

Ishikawa, K., Kubo, T., Shibanoki, S., Matsumoto, A., Hata, H. and Asai, S. (1997) Hippocampal degeneration inducing impairment of learning in rats: model of dementia? Behav. Brain Res. 83, 39-44.

Ishizuka, N., Cowan, W. M. and Amaral, D. G. (1995) A quantitative analysis of the dendritic organization of pyramidal cells in the rat hippocampus. J. comp. Neurol. 362, 17-45.

Jacobs, B. and Scheibel, A. B. (1993) A quantitative dendritic analysis of Wernicke's area in humans. I. Lifespan changes. $J$. comp. Neurol. 327, 83-96.

Jacobs, B., Batal, H. A., Lynch, B., Ojemann, G., Ojemann, L. M. and Scheibel, A. B. (1993a) Quantitative dendritic and spine analyses of speech cortices: a case study. Brain and Language 44, 239-253.

Jacobs, B., Schall, M. and Scheibel, A. B. (1993b) A quantitative dendritic analysis of Wernicke's area in humans. II. Gender, hemispheric, and environmental factors. J. comp. Neurol. 327, $97-111$.

Jerusalinsky, D., Kornisiuk, E. and Izquierdo, I. (1997) Cholinergic neurotransmission and synaptic plasticity concerning memory processing. Neurochem. Res. 22, 507-515.

Jibu, M., Hagan, S., Hameroff, S. R., Pribram, K. H. and Yasue, K. (1994) Quantum optical coherence in cytoskeletal microtubules: implications for brain function. Biosystems 32, 195-209.

Johnson, G. V. W. and Jope, R. S. (1992) The role of microtubule-associated protein 2 (MAP-2) in neuronal growth, plasticity, and degeneration. J. Neurosci. Res. 33, 505-512.

Johnson, G. V. W., Litersky, H. M. and Jope, R. S. (1991) Degradation of microtubule-associated protein 2 and brain spectrin by calpain: a comparative study. J. Neurochem. 56, $1630-1638$.

Kalman, J., Engelhardt, J. I., Le, W. D., Xie, W., Kovacs, I., Kasa, P. and Appel, S. H. (1997) Experimental immunemediated damage of septal cholinergic neurons. $J$ Neuroimmunol. 77, 63-74.
Kleiman, R., Banker, G. and Steward, O. (1994) Development of subcellular mRNA compartmentation in hippocampal neurons in culture. $J$. Neurosci. 14, 1130-1140.

Krnjević, K. and Phillis, J. W. (1963) Acetylcholine-sensitive cells in the cerebral cortex. J. Physiol. 166, 296-327.

Larson, J. and Lynch, G. (1986) Induction of synaptic potentiation in hippocampus by patterned stimulation involves two events. Science 232, 985-988.

Lashley, K. S. (1950) In search of the engram. In: Society for Experimental Biology, Physiological Mechanisms in Animal Behavior, pp. 454-480. Cambridge University Press: Cambridge.

Lezana, G., Muir, J., Nilsson, O. G., Wiley, R. G., Dunnett, S. B. and Bjorklund, A. (1996) Selective immunolesioning of the basal forebrain cholinergic system disrupts short-term memory in rats. Eur. J. Neurosci. 8, 1535-1544.

Lynch, G. and Baudry, M. (1984) The biochemistry of memory: a new and specific hypothesis. Science 224, 1057-1063.

Malach, R. (1992) Dendritic sampling across processing streams in monkey striate cortex. J. comp. Neurol. 315, 303-312.

Maren, S., Aharonoz, G. and Fanselow, M. S. (1996) Retrograde abolition of conditional fear after excitotoxic lesions in the basolateral amygdala of rats: absence of a temporal gradient. Behavioral Neuroscience 110, 718-726.

Matus, A., Bernhardt, R., Bodmer, R. and Alaimo, D. (1986) Microtubule-associated protein 2 and tubulin are differently distributed in the dendrites of developing neurons. Neuroscience $17,371-389$

Mayford, M., Bach, M. E., Huang, Y. Y., Wang, L., Hawkins, R. D. and Kandel, E. R. (1996) Control of memory formation through regulated expression of a CaMKII transgene. Science 274, 1678-1683.

McAdam, D., Knott, J. R. and Chiorini, J. (1965) Classical conditioning in the cat as a function of the CS-US interval. Psychonomic Sci. 3, 89-90.

McAllister, W. R. (1943) Eyelid conditioning as a function of the CS-US interval. J. Exp. Psych. 45, 417-422.

McMahan, R. W., Sobel, T. J. and Baxter, M. G. (1997) Selective immunolesions of hippocampal cholinergic input fail to impair spatial working memory. Hippocampus 7, 130-136.

Mednikova, Y. S. (1990) The influence of microiontophoretic application of acetylcholine on the formation of conditioned reactions of neurons of the motor cortex. Neurosci. Behav. Physiol. 20, $310-316$

Mesulam, M.-M. (1996) The systems-level organization of cholinergic innervation in the human cerebral cortex and its alterations in Alzheimer's disease. Prog. Brain Res. 109, 285-297.

Mesulam, M.-M., Brimijoin, S. and Geula, C. (1994) Neurofibrillary tangles have no obligatory predilection for acetylcholinesterase-rich neurons. Neurobiol. Aging 15, 615-619.

Mesulam, M.-M. and Geula, C. (1991) Differential distribution of a neurofilament protein epitope in acetylcholinesterase-rich neurons of human cerebral neocortex. Brain Res. 544, 169-173.

Milov, A. M., Schweitzer, E. S. and Woolf, N. J. (1997) NGF is transiently increased in hippocampus during consolidation of contextual memory. Soc. Neurosci. Abstr., 23.

Molinengo, L. (1993) The action of scopolamine on retrieval and memory storage in rats evaluated in the staircase maze. Behav. Neur. Biol. 59, 18-24.

Morales, M. and Fifkova, E. (1989) Distribution of MAP2 in dendritic spines and its colocalization with actin. An immunogold electron-microscope study. Cell Tis. Res. 256, 447-456.

Moran, P. M. (1993) Differential effects of scopolamine and mecamylamine on working and reference memory in the rat. Pharm. Biochem. Behav. 45, 533-538.

Morrison, J. H., Lewis, D. A., Campbell, M. J., Huntley, G. W. Benson, D. L. and Bouras, C. (1987) A monoclonal antibody to non-phosphorylated neurofilament protein marks the vulnerable cortical neurons in Alzheimer's disease. Brain Res. 416, 331336.

Mountcastle, V. B. (1978) An organizing principle for cerebra function: The unit module and the distributed system. In The Mindful Brain. Eds G. M. Edelman and V. B. Mountcastle. MIT Press: Cambridge, MA

Mrzljak, L., Uylings, H. B., Van Eden, C. G. and Judas, M. (1990) Neuronal development in human prefrontal cortex in prenatal and postnatal stages. Prog. Brain Res. 85, 185-222.

Muir, J. L. (1997) Acetylcholine, aging, and Alzheimer's disease. Pharm. Biochem. Behav. 56, 687-696.

Müller, W. and Connor, J. A. (1991) Cholinergic input uncouples $\mathrm{Ca}^{2+}$ changes from $\mathrm{K}^{+}$conductance activation and amplifies intradendritic $\mathrm{Ca}^{2+}$ changes in hippocampal neurons. Neuron $\mathbf{6}$, 901-905. 
Müller, W., Petrozzino, J. J., Griffith, L. C., Danho, W. and Connor, J. A. (1992) Specific involvement of $\mathrm{Ca}^{2+}$ )-calmodulin kinase II in cholinergic modulation of neuronal responsiveness. J. Neurophysiol. 68, 2264-2269.

Murai, S., Saito, H., Masuda, Y., Odashima, J. and Itoh, T. (1995) AF64A disrupts retrieval processes in long-term memory of mice. Neuroreport 6, 349-352.

Myers, C. E., Ermita, B. R., Harris, K., Hasselmo, M., Solomon, P. and Gluck, M. A. (1996) A computational model of cholinergic disruption of septohippocampal activity in classical eyeblink conditioning. Neurobiol. Learn. Memory 66, 51-66.

Napier, R. M., Macrae, M. and Kehoe, E. J. (1992) Rapid reacquisition in conditioning of the rabbit's nictitating membrane response. J. Exp. Psychol.: Animal Behav. Proc. 18, 182-192.

Newman, S. K., Warrington, E. K., Kennedy, A. M. and Rossor, M. N. (1994) The earliest cognitive change in a person with familial Alzheimer's disease: presymptomatic neuropsychological features in a pedigree with familial Alzheimer's disease confirmed at necropsy. J. Neurol. Neurosurg. Psychiat. 57, 967-972.

Nonner, D., Barrett, E. F. and Barrett, J. N. (1996) Neurotrophin effects on survival and expression of cholinergic properties in cultured rat septal neurons under normal and stress conditions. J. Neurosci. 16, 6665-6675.

Offermanns, S., Bombien, E. and Schultz, G. (1993) Stimulation of tyrosine phosphorylation and mitogen-activated-protein (MAP) kinase activity in human SH-SY5Y neuroblastoma cells by carbachol. Biochem. J. 294, 545-550.

Oh, J. D., Edwards, R. H. and Woolf, N. J. (1996) Choline acetyltransferase mRNA plasticity with Pavlovian conditioning. Exp. Neurol. 140, 95-99.

Ohno, M., Kobayashi, M., Kishi, A. and Watanabe, S. (1997) Working memory failure by combined blockade of muscarinic andbeta-adrenergic transmission in the rat hippocampus. Neuroreport 8, 1571-1575.

Ortega, A., del Guante, M. A., Prado-Alcala, R. A. and Aleman, V. (1996) Changes in rat brain muscarinic receptors after inhibitory avoidance learning. Life Sci. 58, 799-809.

Palmer, A. M. (1996) Neurochemical studies of Alzheimer's disease. Neurodegeneration 5, 381-391.

Pandya, D. N. and Yeterian, E. H. (1985) Architecture and connections of cortical association areas. In: Cerebral Cortex, Vol. 4, pp. 3-61, Eds A. Peter and E. G. Jones. Plenum Press: New York.

Papa, M. and Segal, M. (1996) Morphological plasticity in dendritic spines of cultured hippocampal neurons. Neuroscience 71, $1005-1011$.

Payne, B. R. and Peters, A. (1989) Cytochrome oxidase patches and Meynert cells in monkey visual cortex. Neuroscience 28, 353-363.

Pedarzani, P. and Storm, J. F. (1996) Evidence that Ca/calmodulin-dependent protein kinase mediates the modulation of $\mathrm{Ca}^{2+}$ dependent $\mathrm{K}^{+}$current, IAHP, by acetylcholine, but not by glutamate, in hippocampal neurons. Pflugers Arch. Eur. J. Physiol. 431, 723-728.

Perry, E. K., Tomlinson, B. E., Blessed, G., Bergmann, K., Gibson, P. H. and Perry, R. H. (1978) Correlation of cholinergic abnormalities with senile plaques and mental test scores in senile dementia. Brit. Med. J. 2, 1457-1459.

Pirch, J. H., Turco, K. and Rucker, H. K. (1992) A role for acetylcholine in conditioning-related responses of rat frontal cortex neurons: microiontophoretic evidence. Brain Res. 586, $19-26$.

Price, J. L. and Stern, R. (1983) Individual cells in the nucleus basalis-diagonal band complex have restricted axonal projections to the cerebral cortex in the rat. Brain Res. 269, 352-356.

Quinlan, E. M. and Halpain, S. (1996) Postsynaptic mechanisms for bidirectional control of MAP2 phosphorylation by glutamate receptors. Neuron 16, 357-368.

Reid, S. N. and Daw, N. W. (1995) Dark-rearing changes dendritic microtubule-associated protein 2 (MAP2) but not subplate neurons in cat visual cortex. J. comp. Neurol. 359, 38-47.

Rescorla, R. A. (1997) Spontaneous recovery after Pavlovian conditioning with multiple outcomes. Animal Learn. Behav. 25, 99 107.

Ridley, R. M. and Baker, H. F. (1997) Evidence for a specific information processing deficit in monkeys with lesions of the septo-hippocampal system. Cortex 33, 167-176.

Riekkinen, M. and Riekkinen, P., Jr. (1997) Dorsal hippocampal muscarinic acetylcholine and NMDA receptors disrupt water maze navigation. Neuroreport 8, 645-648.
Rigdon, G. C. and Pirch, J. H. (1986) Nucleus basalis involvement in conditioned neural responses in the rat frontal cortex. $J$. Neurosci. 6, 2535-2542.

Rosene, D. L. and Van Hoesen, G. W. (1987) The hippocampal formation of the primate brain: A review of some comparative aspects of cytoarchitecture and connections. In: Cerebral Cortex, Vol. 6, pp. 345-456. Eds A. Peter and E. G. Jones. Plenum Press: New York.

Rosenzweig, M. R. and Bennett, E. L. (1996) Psychobiology of plasticity: effects of training and experience on brain and behavior. Behav. Brain Res. 78, 57-65.

Rosenzweig, M. R., Bennett, E. L. and Diamond, M. C. (1972) Brain changes in response to experience. Sci. Am. 226, 22-29.

Rotenberg, A., Mayford, M., Hawkins, R. D., Kandel, E. R. and Muller, R. U. (1996) Mice expressing activated CaMKII lack low frequency LTP and do not form stable place cells in the CA1 region of the hippocampus. Cell 87, 1351-1361.

Rusted, J. M. and Warburton, D. M. (1989) Effects of scopolamine on verbal memory, a retrieval or acquisition deficit? Neuropsychobiology 21, 76-83.

Samuel, W., Terry, R. D., DeTeresa, R., Butters, N. and Masliah, E. (1994) Clinical correlates of cortical and nucleus basalis pathology in Alzheimer dementia. Arch. Neurology 51, 772-778.

Saper, C. B. (1984) Organization of cerebral cortical afferent systems in the rat. I. Magnocellular basal nucleus. J. comp. Neurol. 222, 313-342.

Sarter, M. and Bruno, J. P. (1997) Cognitive functions of cortical acetylcholine: toward a unifying hypothesis. Brain Res. Rev. 23 , 28-46.

Segal, M. and Auerbach, J. M. (1997) Muscarinic receptors involved in hippocampal plasticity. Life Sci. 60, 1085-1091.

Segal, R. A. and Greenberg, M. E. (1996) Intracellular signaling pathways activated by neurotrophic factors. Ann. Rev. Neurosci. 19, 463-489.

Seligman, M. E. (1970) On the generality of the laws of learning. Psychol. Rev. 77, 406-418.

Shen, J., Barnes, C. A., Wenk, G. L. and McNaughton, B. L. (1996) Differential effects of selective immunotoxic lesions of medial septal cholinergic cells on spatial working and reference memory. Behav. Neurosci. 110, 1181-1186.

Siegel, G. J., Agranoff, B. W., Albers, R. W. and Molinoff, P. B. (1994) Basic Neurochemistry. Raven Press: New York.

Squire, L. R. (1986) Mechanisms of memory. Science 232, 1612 1619.

Stewart, R., Erskine, L. and McCaig, C. D. (1995) Calcium channel subtypes and intracellular calcium stores modulate electric field-stimulated and -oriented nerve growth. Dev. Biol. 171, 340-351.

Stoehr, J. D., Mobley, S. L., Roice, D., Brooks, R., Baker, L. M. Wiley, R. G. and Wenk, G. L. (1997) The effects of selective cholinergic basal forebrain lesions and aging upon expectancy in the rat. Neurobiol. Learn. Memory 67, 214-227.

Stofko-Hahn, R. E., Carr, D. W. and Scott, J. D. (1992) A single step purification for recombinant proteins. Characterization of a microtubule associated protein (MAP 2) fragment which associates with the type II cAMP-dependent protein kinase. Febs Letters 320, 274-278.

Takei, N., Kuramoto, H., Endo, Y. and Hatanaka, H. (1997) NGF and BDNF increase the immunoreactivity of vesicular acetylcholine transporter in cultured neurons from the embryonic rat septum. Neurosci. Letts. 226, 207-209.

Tanzi, E. (1893) I fatti e le induzioni nell'odiernaistilogia del sistema nervosa. Riv. Sper. Freniat. Med. Alienazioni. Ment. 19, 419-472.

Thoenen, H., Zafra, F., Hengerer, B. and Lindholm, D. (1991) The synthesis of nerve growth factor and brain-derived neurotrophic factor in hippocampal and cortical neurons is regulated by specific transmitter systems. Ann. New York Acad. Sci. 640, $86-90$

Tieman, S. B. and Hirsch, H. V. B. (1982) Exposure to lines of only one orientation modifies dendritic morphology of cells in the visual cortex of the cat. J. comp. Neurol. 211, 353-362.

Toumane, A. and Durkin, T. P. (1993) Time gradient for post-test vulnerability to scopolamine-induced amnesia following the initial acquisition session of a spatial reference memory task in mice. Behav. Neur.Biol. 60, 139-151.

Tuszynski, M. H. and Gage, F. H. (1995) Bridging grafts and transient nerve growth factor infusions promote long-term central nervous system neuronal rescue and partial functional recovery. PNAS 92, 4621-4625.

Van Der Zee, E. A., Douma, B. R. K., Bohus, B. and Luiten, P. G. M. (1994) Passive avoidance training induces enhanced levels 
of immunoreactivity for muscarinic acetylcholine receptor and coexpressed PCK $\gamma$ and MAP-2 in rat cortical neurons. Cerebral Cortex 4, 376-390.

Vanderwolf, C. H. (1987) Near-total loss of "learning" and "memory" as a result of combined cholinergic and serotonergic blockade in the rat. Behav. Brain Res. 23, 43-57.

Vannucchi, M. G. and Pepeu, G. (1995) Muscarinic receptor modulation of acetylcholine release from rat cerebral cortex and hippocampus. Neurosci. Letts. 190, 53-56.

Vitiello, B., Martin, A., Hill, J., Mack, C., Molchan, S., Martinez, R., Murphy, D. L. and Sunderland, T. (1997) Cognitive and behavioral effects of cholinergic, dopaminergic, and serotonergic blockade in humans. Neuropsychopharmacology 16, 15-24.

Wainer, B. H. and Mesulam, M.-M. (1990) Ascending cholinergic pathways in the rat brain. In Brain Cholinergic Systems, pp. 65119. Eds M. Steriade and D. Biesold. Oxford University Press: New York.

Waite, J. J., Chen, A. D., Wardlow, M. L., Wiley, R. G., Lappi, D. A. and Thal, L. J. (1995) 192 immunoglobulin G-saporin produces graded behavioral and biochemical changes accompanying the loss of cholinergic neurons of the basal forebrain and cerebellar Purkinje cells. Neuroscience 65, 463-476.

Wallace, C. S., Withers, G. S., Weiler, I. J., George, J. M., Clayton, D. F. and Greenough, W. T. (1995) Correspondence between sites of NGFI-A induction and sites of morphological plasticity following exposure to environmental complexity. Mol Brain Res. 32, 211-220.

Walsh, T. J., Herzog, C. D., Gandhi, C., Stackman, R. W. and Wiley, R. G. (1996) Injection of IgG 192-saporin into the medial septum produces cholinergic hypofunction and dose-dependent working memory deficits. Brain Res. 726, 69-79.

Wenk, G. L. (1997) The nucleus basalis magnocellularis cholinergic system: one hundred years of progress. Neurobiol. Learn. Memory 67, 85-95.

Wesnes, K. and Warburton, D. M. (1984) Effects of scopolamine and nicotine on human rapid information processing performance. Psychopharmacology 82, 147-150.

Whitehouse, P. J., Price, D. L., Clark, A. W., Coyle, J. T. and DeLong, M. R. (1981) Alzheimer disease: evidence for selective loss of cholinergic neurons in the nucleus basalis. Ann. Neurol. 10, 122-126.

Winfield, D. A., Neal, J. W. and Powell, T. P. (1983) The basal dendrites of Meynert cells in the striate cortex of the monkey. Proc. Royal Soc. Lond. Series B: Biol. Sci. 217, 29-39.
Winkler, J. and Thal, L. J. (1995) Effects of nerve growth factor treatment on rats with lesions of the nucleus basalis magnocelluaris produced by ibotenic acid, quisqualic acid, and AMPA. Exp. Neurol. 136, 234-250.

Woolf, N. J. (1991) Cholinergic systems in the mammalian brain and spinal cord. Prog. Neurobiol. 37, 475-524.

Woolf, N. J. (1992) Choline acetyltransferase fibers in the striate cortex of vertical and horizontal stripe-reared kittens preferentially develop orthogonal to the selected visual orientation. Soc Neurosci. Abstr. 18, 1315.

Woolf, N. J. (1993) Cholinoceptive cells in rat cerebral cortex: somatodendritic immunoreactivity for muscarinic receptor and cytoskeletal proteins. J. Chem. Neuroant. 6, 375-390.

Woolf, N. J. (1996a) Global and serial neurons form a hierarchically-arranged interface proposed to underlie memory and cognition. Neuroscience 74, 625-651.

Woolf N. J. (1996b) The critical role of cholinergic basal forebrain neurons in morphological change and memory encoding: a hypothesis. Neurobiol. Learn. Memory 66, 258-266.

Woolf, N. J. (1997) A possible role for cholinergic neurons of the basal forebrain and pontomesencephalon in consciousness. Consciousness and Cognition, in press.

Woolf, N. J. and Butcher, L. L. (1986) Cholinergic systems in the rat brain: III. Projections from the pontomesencephalic tegmentum to the thalamus, tectum, basal ganglia, and basal forebrain. Brain Res. Bull. 16, 603-637.

Woolf, N. J. and Butcher, L. L. (1990) Dysdifferentiation of structurally plastic neurons initiates the pathologic cascade of Alzheimer's disease: toward a unifying hypothesis. In Brain Cholinergic Systems, pp. 387-438. Eds M. Steriade and D. Biesold. Oxford University Press: New York.

Woolf, N. J., Eckenstein, F. and Butcher, L. L. (1983) Cholinergic projections from the basal forebrain to the frontal cortex: A combined fluorescent tracer and immunohistochemical analysis. Neurosci. Lett. 40, 93-98.

Woolf, N. J., Eckenstein, F. and Butcher, L. L. (1984) Cholinergic systems in the rat brain: I. Projections to the limbic telencephalon. Brain Res. Bull. 13, 751-784.

Woolf, N. J., Young, S. L., Johnson, G. V. W. and Fanselow, M. S. (1994) Pavlovian conditioning alters microtubule-associated protein-2. NeuroReport 5, 1045-1048.

Woolf, N. J., Zinnerman, M. D. and Johnson, G. V. W. (1996) Signs of MAP-2 degradation in the hippocampus with contextual memory. Soc. Neurosci. Abstr. 22, 440. 